\title{
On the Profitability of Cross-Ownership in Cournot Oligopolies: Stock Sizes Matter
}

HASSAN BENCHEKROUN MIAO DAI NGO VAN LONG 


\section{$\checkmark$ CIRANO Knowledge into action}

Center for Interuniversity Research and Analysis on Organizations

The purpose of the Working Papers is to disseminate the results of researcil conducted by ŨIkANO research menvers in order to solicit exchanges and comments. These reports are written in the style of scientific publications. The ideas and opinions expressed in these documents are solely those of the authors.

Les cahiers de la série scientifique visent à rendre accessibles les résultats des recherches effectuées par des chercheurs membres du CIRANO afin de susciter échanges et commentaires. Ces cahiers sont rédigés dans le style des publications scientifiques et n'engagent que leurs auteurs.

CIRANO is a private non-profit organization incorporated under the Quebec Companies Act. Its infrastructure and research activities are funded through fees paid by member organizations, an infrastructure grant from the government of Quebec, and grants and research mandates obtained by its research teams.

Le CIRANO est un organisme sans but lucratif constitué en vertu de la Loi des compagnies du Québec. Le financement de son infrastructure et de ses activités de recherche provient des cotisations de ses organisations-membres, d'une subvention d'infrastructure du gouvernement du Québec, de même que des subventions et mandats obtenus par ses équipes de recherche.

\section{CIRANO Partners - Les partenaires du CIRANO}

Corporate Partners - Partenaires corporatifs

Autorité des marchés financiers

Bank of Canada

Bell Canada

BMO Financial Group

Business Development Bank of Canada

Caisse de dépôt et placement du Québec

Desjardins Group

Énergir

Hydro-Québec

Innovation, Science and Economic Development Canada

Intact Financial Corporation

Manulife Canada

Ministère de l'Économie, de la Science et de l'Innovation

Ministère des finances du Québec

National Bank of Canada

Power Corporation of Canada

PSP Investments

Rio Tinto

Ville de Montréal

Academic Partners - Partenaires universitaires

Concordia University

École de technologie supérieure

École nationale d'administration publique

HEC Montréal

McGill University

National Institute for Scientific Research

Polytechnique Montréal

Université de Montréal

Université de Sherbrooke

Université du Québec

Université du Québec à Montréal

Université Laval

CIRANO collaborates with many centers and university research chairs; list available on its website. Le CIRANO collabore avec de nombreux centres et chaires de recherche universitaires dont on peut consulter la liste sur son site web.

(C) August 2020. Hassan Benchekroun, Miao Dai, Ngo Van Long. All rights reserved. Tous droits réservés. Short sections may be quoted without explicit permission, if full credit, including (C) notice, is given to the source. Reproduction partielle permise avec citation du document source, incluant la notice ().

The observations and viewpoints expressed in this publication are the sole responsibility of the authors; they do not necessarily represent the positions of CIRANO or its partners. Les idées et les opinions émises dans cette publication sont sous l'unique responsabilité des auteurs et ne représentent pas nécessairement les positions du CIRANO ou de ses partenaires. 


\title{
On the Profitability of Cross-Ownership in Cournot Oligopolies: Stock Sizes Matter *
}

\author{
Hassan Benchekroun ', Miao Dai *, Ngo Van Long ${ }^{\S}$
}

\begin{abstract}
We examine the profitability of cross-ownership in an oligopolistic industry where firms compete as Cournot rivals. We consider a symmetric cross-ownership structure in which a subset of $\mathrm{k}$ firms engage in crossshareholding and each firm has an equal silent financial interest in the other firms, while the remaining $(\mathrm{n}-\mathrm{k})$ firms stay independent. We show that a symmetric cross-ownership is never profitable for any levels of noncontrolling minority shareholdings if the participation ratio $(k / n)$ is less than or equal to $(n+1) /(2 n)$, while there exists a large range of cross-ownership for which it can be profitable beyond that participation ratio. This result may be called a cross-ownership paradox, analogous to the merger paradox. With the presence of stock constraints, however, we find some of the results from the cross-ownership paradox do not carry over to the case of non-renewable resource industries. The profitability of a symmetric cross-ownership can be positive even when the participation ratio $(\mathrm{k} / \mathrm{n})$ is less than or equal to $(\mathrm{n}+1) /(2 \mathrm{n})$ and is always positive when the participation ratio $(\mathrm{k} / \mathrm{n})$ is greater than $(\mathrm{n}+1) /(2 \mathrm{n})$, provided that the initial resource stock owned by each firm is small enough. We also highlight that cross-ownership can be preferable to a horizontal merger under Cournot competition. Not only is it more profitable to do so, more importantly, it constitutes a shrewd strategy to avoid possible legal challenges.
\end{abstract}

Keywords: Cross-ownership, Profitability, Oligopoly, Non-renewable Resources, Resource Stock, Horizontal Merger, Competition Policy, Antitrust Laws

JEL Codes: L13, L41, Q3

\section{Résumé}

Nous examinons la rentabilité de la propriété croisée dans une industrie oligopolistique où les entreprises se font concurrence en tant que rivales de Cournot. Nous considérons une structure de propriété croisée symétrique dans laquelle un sous-ensemble de $\mathrm{k}$ entreprises s'engagent dans des participations croisées, chaque entreprise ayant un intérêt financier silencieux égal dans les autres (k-1) entreprises du sous-ensemble, alors que $(\mathrm{n}-\mathrm{k})$ entreprises restent indépendantes. Nous montrons qu'une participation croisée symétrique n'est jamais rentable si le ratio de participation $(k / n)$ est inférieur ou égal à $(n+1) /(2 n)$, alors qu'il existe un large domaine de valeurs de $\mathrm{k} / \mathrm{n}$ au-delà de $(\mathrm{n}+1) /(2 \mathrm{n})$ pour lesquelles la participation croisée est rentable. Ce résultat peut être qualifié de paradoxe de la propriété croisée, analogue au paradoxe de la fusion. Cependant, dans le cas des industries de ressources non-renouvelables, avec la présence de contraintes de stock, nous constatons que certains des résultats du paradoxe de la propriété croisée ne se répercutent pas. La rentabilité d'une propriété croisée symétrique peut être positive même lorsque le taux de participation $(\mathrm{k} / \mathrm{n})$ est inférieur ou égal à $(\mathrm{n}+1) /(2 \mathrm{n})$ et est toujours positive lorsque le taux de participation $(\mathrm{k} / \mathrm{n})$ est supérieur à $(\mathrm{n}+1) /$ (2n), à condition que le stock initial de ressources détenu par chaque entreprise soit suffisamment petit. Nous soulignons également que la propriété croisée peut être préférable à une fusion horizontale sous la concurrence de Cournot. Non seulement il est plus rentable de le faire, mais surtout, cela constitue une stratégie astucieuse pour éviter d'éventuelles contestations judiciaires.

Mots-clés : Propriété croisée, Rentabilité, Oligopole, Ressources non-renouvelables, Stock de ressources, Fusion horizontale, Politique de la concurrence, Lois antitrust

Codes JEL : L13, L41, Q3

\footnotetext{
* Acknowledgement: The authors gratefully acknowledge the research grants from Fonds de Recherche du Québec- Société et Culture (FRQSC) and from the Social Sciences and Humanities Research Council of Canada (SSHRC).

$\dagger$ hassan.benchekroun@mcgill.ca. Department of Economics, McGill University.

\$ miao.dai@mail.mcgill.ca. Department of Economics, McGill University.

$\S$ ngo.long@mcgill.ca. CIRANO, and Department of Economics, McGill University.
} 


\section{Introduction}

The past few decades have witnessed a phenomenal growth of passive private equity investments between rival firms within the same industry, whereby they engage in cross-shareholdings and participate in various forms of co-operation. These activities create the so-called cross-ownership structure that has characterized the complex economic ties and deep-rooted corporate relations among competing firms across nearly every sector. Notable examples include the global automobile industries (Alley, 1997; Ono et al., 2004), ${ }^{1}$ the Dutch Financial Sector (Dietzenbacher, Smid and Volkerink, 2000), the Nordic power market (Amundsen and Bergman, 2002), the Italian national banking sector (Trivieri, 2007) and the pay-TV markets in Norway and Sweden (Foros, Kind and Shaffer, 2011). The first research question addressed in this paper is thus to understand the incentives of rival firms to participate in cross-ownership, and the levels of cross-shareholdings that will be profitable in these industries.

Previous studies on cross-ownership have focused mainly on the potential anticompetitive effects induced by cross-ownership, i.e., unilateral effects (Reynolds and Snapp, 1986; Bresnahan and Salop, 1986; Farrell and Shapiro, 1990; Flath, 1991, 1992; O'Brien and Salop, 2000; Dietzenbacher, Smid and Volkerink, 2000; Brito, Cabral and Vasconcelos, 2014; Brito, Ribeiro and Vasconcelos, 2014; Brito et al., 2018) and coordinated effects (Malueg, 1992; Gilo, Moshe and Spiegel, 2006; Brito, Ribeiro and Vasconcelos, 2018), and have thus proposed various modified measurement indexes — the Herfindahl-Hirschman Index and the Gross Upward Price Pressure Index — to account for it. However, what is missing in the literature is why and to what extent firms want to engage in cross-shareholdings.

To address this gap, our paper considers a k-symmetric cross-ownership structure in an n-firm Cournot homogeneous-product model where a subset of $k \leq n$ firms engage in rival cross-shareholding and each firm has an equal silent financial interest in the other firms, while the remaining $n-k$ firms stay independent. By examining the profitability of a $\mathrm{k}$-symmetric cross-ownership, we show that for any levels of non-controlling minority shareholdings, a

\footnotetext{
${ }^{1}$ For example, Renault has formed a strategic alliance with Nissan and Mitsubishi in which Renault currently holds a $43.4 \%$ equity stake in Nissan and Nissan owns a $15 \%$ stake in Renault and 34\% stake in Mitsubishi. Toyota has added a group of competitors to its growing list of partners; currently it owns a $5.1 \%$ stake in Mazda, a $20 \%$ stake in Subaru and a $4.94 \%$ stake in Suzuki, and in return Mazda takes a $0.25 \%$ stake, Suzuki takes a $0.2 \%$ stake in Toyota, respectively. Honda is investing $\$ 2.75$ billion and takes a 5.7 percent stake in GM's Cruise self-driving unit. Ford and Volkswagen have said they will spend billions of dollars to jointly develop electric and self-driving vehicles.
} 
$\mathrm{k}$-symmetric cross-ownership is never profitable if the participation ratio $\frac{k}{n}$ is less than or equal to $\frac{1}{2}\left(\frac{n+1}{n}\right)$, while there exists a large range of cross-ownership for which it can be profitable beyond that participation ratio. This result seems surprising as one would naturally think it should be always profitable for firms to participate in cross-ownership. We thus define this result as a cross-ownership paradox, analogous to the merger paradox. In general, firms have no incentive to engage in cross-shareholdings if less than $50 \%$ of the firms in the industry participate. However, beyond that participation ratio, for example, with $n=10$ and $k=6$, cross-ownership is profitable provided that each of the 6 firms holds no more than $6.5 \%$ of the shares of any other firm; with $n=9$ and $k=6$, cross-ownership is profitable provided that each of the 6 firms holds no more than $12.5 \%$ of the shares of any other firm, and with $n=8$ and $k=6$, cross-ownership is always profitable for any non-controlling minority shareholdings. Thus a k-symmetric cross-ownership is more likely to be profitable with lower levels of shareholdings for a lower participation ratio. The main intuition behind the result can be explained by cross-ownership theory and oligopoly theory. When a firm acquires a partial financial interest in a rival, it has an incentive to compete less aggressively and thus unilaterally reduce its output. A larger shareholding by the firms that engage in the symmetric cross-ownership will induce them to reduce output by more, triggering a more aggressive response by the outsiders in terms of strategic substitutes in Cournot competition. The increase in both the number and output of the outsiders more than offsets the benefit the cross-owners can receive from their reduction of output, thereby reducing the profitability of cross-ownership.

Nonrenewable resource industries have stood out among other industries, as the volume of mergers and acquisitions has been historically and consistently much higher (Kumar, 2012; Benchekroun, Breton and Chaudhuri, 2019). That sector has experienced a widely documented cross-ownership. For example, in the oil and gas industry, the top six multinational oil companies, i.e., ExxonMobile, British Petroleum (BP), Royal Dutch Shell, Chervon, Total and Eni, are more closely interconnected with each other than would be expected. ${ }^{2}$ According to a report by Water Street Partners based on the source from Rystad Energy, ${ }^{3}$ intriguingly large amounts of supermajor-to-supermajor joint-ventures exist in the production stage, let

\footnotetext{
${ }^{2}$ Other notable examples include: BP holds a $19.75 \%$ stake in the Russian oil giant Rosneft; the Mexican state-owned petroleum company Pemex holds a 9.3\% stake in the Spanish oil giant Repsol; China's state-owned Sinopec holds a 30\% stake in Petrogal Brasil, and 40\% in Repsol YPF Brasil, respectively.

${ }^{3}$ https : //www . waterstreetpartners . net/blog/the-web-of-partnerships-between-bp-chevron-eni-exxonmobil
} 
alone other stages such as exploration, refining, distributing and retailing. A second question arises as to why so much cross-ownership occurs in the exhaustible resource sector and what best explains the phenomenon. Despite the well-established and extensive literature on resource economics, no previous studies have investigated how ownership links between any rival firms may affect the use of a nonrenewable resource. Thus, our third objective is to examine how the presence of cross-ownership affects market competition and thus firms' extraction paths in the nonrenewable resource sector, and investigate whether it will give rise to market power.

The nonrenewable resource sector differs from other sectors because the use of a nonrenewable resource is inherently a dynamic problem that cannot be solved using a static model. That is, the output of each resource extracting firm, i.e., their cumulative extraction over time, is constrained by their limited initial resource stocks. As a result, current extraction and production affect the availability of reserves for future extraction and production (Hotelling, 1931). Applying the static models from the cross-ownership literature directly to the nonrenewable resource industries would be inappropriate. Ignoring dynamic effects may even produce spurious results, as observed by Benchekroun and Gaudet (2003) and Benchekroun, Breton and Chaudhuri (2019), who all find that the static results in a generic industry often do not carry over to the nonrenewable industries. Moreover, neglecting the supply-side dynamics can even give inaccurate policy implications. Ryan (2012) evaluates the welfare costs of the 1990 Amendments to the Clean Air Act on the U.S. Portland cement industry, and argues that in industries where fixed costs are an important determinant of market structure, a static analysis ignores the dynamic effects of the regulation on entry, investment, and market power. Accounting for these effects through a dynamic model of oligopoly, he shows that a static analysis misses the welfare penalty on consumers, and obtains the wrong sign of the welfare effects on incumbent firms (Ryan, 2012). Further addressing this issue, Watkins (2019) shows that in an oligopolistic market with a recyclable good, if some of the inputs are used to manufacture a good that competes with the original good, the initial seller has an incentive to reduce its supply to limit this source of future competition. Ignoring these types of dynamic incentives would lead antitrust authorities to underestimate both the elasticity of demand and the price increase post-merger.

Since the nonrenewable resource sector requires a specific analysis, we thus use a dynamic 
game model in which firms compete à la Cournot while each firm faces a resource stock constraint. We use a continuous time framework with an endogenous time horizon. Following much of the existing literature on oligopoly models of nonrenewable resource markets (Salant, 1976; Lewis and Schmalensee, 1980; Loury, 1986; Benchekroun, Halsema and Withagen, 2009, 2010; Benchekroun, Breton and Chaudhuri, 2019), we adopt the open-loop strategies by which firms commit to a fixed time path of extraction. ${ }^{4}$ We then characterize an open-loop Nash-Cournot cross-ownership equilibrium (OL-NCOE) of the game and investigate the profitability of a k-symmetric cross-ownership under this context. We find that a k-symmetric cross-ownership can be profitable even when the participation ratio $\frac{k}{n}$ is less than or equal to $\frac{1}{2}\left(\frac{n+1}{n}\right)$ and is always profitable when the participation ratio $\frac{k}{n}$ is greater than $\frac{1}{2}\left(\frac{n+1}{n}\right)$, provided that the initial resource stock owned by each firm is small enough. Moreover, the profitability increases in levels of cross-ownership when resource stock owned by each firm is small. This result sharply contrasts with the static model in which lower levels of cross-ownership seem more profitable. Unlike the static model in which outsiders respond to any increased shareholdings between cross-owners by aggressively increasing output and mitigating the cross-ownership participants' gain in market power, the limited resource stocks restrict the outsiders in their response. Consequently, when the stock is sufficiently small, a higher level of cross-ownership will generate a higher profitability.

In addition, a k-symmetric cross-ownership results in a slower extraction rate for the industry and induces the outsiders to exhaust their stocks earlier than the cross-ownership participants at any resource stock level. These findings indicate that the degree of concentration in supply will increase over time, and a group of cross-owners will eventually supply the resource before exhaustion. This result resembles the 'oil'igopoly theory (Loury, 1986; Polasky, 1992), which predicts that small firms will exhaust their stocks before large firms do, leading possibly to eventual monopolization of the market. The increased concentration over time induced by

\footnotetext{
${ }^{4} \mathrm{We}$ acknowledge that OLNE is only time-consistent but not subgame perfect. If firms have all the information about its own and competitors' stocks at any future dates, they would be able to adjust their production at each instant of time, i.e., use closed-loop or Markov strategies. However, there are several reasons to justify the use of OLNE as noted in Benchekroun, van der Meijden and Withagen (2019). The first justification is the analytical tractability, as one has to resort to numerical methods to characterize a closed-loop equilibrium, but such methods suffer from the curse of dimensionality. The second is the prevalence of long-term contracts in nonrenewable resource markets so that actual extraction rates do not only depend on the actual resource stocks but also from the pre-committed supplies. Finally the size of existing resource stocks are unusually uncertain, not only to competitors but may also to resource owners. It would be challenging to fully account for the closed-loop equilibrium as it requires information on the vector of stocks at each moment.
} 
cross-ownership confers market power on those cross-owners. As such, the cross-ownership participants can raise prices more than in other industries without stock constraint, which provides an additional incentive to look at the exhaustible sector differently.

Our paper also contrasts cross-ownership with horizontal mergers. One of the seminal works in the literature is arguably the paper by Salant, Switzer and Reynolds (1983), who show that the seemingly profitable mergers between competing firms in the same industry can be unprofitable, which is known as the merger paradox. More specifically, when firms compete à la Cournot in an oligopolistic industry with linear demand and constant marginal cost of production, horizontal mergers are not profitable unless at least $80 \%$ of the industry participates in the merger. Since cross-ownership is often referred to as "partial mergers", one would often wonder why firms do not engage in a full merger in the first place, as a merger totally eliminates the previous rivalry and can pool resources more efficiently. Foros, Kind and Shaffer (2011) answer this question by showing that in a spatial Salop 3-firm Bertrand model with differentiated products, the profitability of a partial cross-ownership that gives the acquirer corporate control over all pricing decisions could be much higher than that of a full merger because a partial ownership arrangement can greatly dampen competition when the firms' choices are strategic complements. Stühmeier (2016) extends their 3-firm setting with four or more firms, only to find that firms prefer a merger to a partial acquisition, because both neighbors to the entity respond differently to the acquisition. Thus he concludes that whether partial acquisition is preferred than a merger is sensitive to the intensity of competition in the market. However, these papers only consider Bertrand competition whereas there are numerous industries in which firms compete in a way that is more consistent with Cournot competition. Using models with price competition to investigate quantity competition would often end up with unreliable results and give misleading policy implications. Our paper thus provides a possible explanation as to why cross-ownership is preferable to a full merger in terms of Cournot competition. For example, when $k=6$ and $n=10$, cross-ownership is profitable provided that each of the 6 firms holds no more than $6.5 \%$ of the non-controlling minority shares of any other firm, while a horizontal merger of 6 firms is unprofitable.

This result also bears some practical considerations from a company's corporate strategy point of view. Not only is it more profitable to participate in the cross-ownership than a 
horizontal merger, more importantly, it constitutes a "smart" way to avoid the possible legal challenges. While horizontal mergers are subject to substantial antitrust scrutiny and are often opposed by antitrust authorities, non-controlling minority shareholdings are either granted a de facto exemption from antitrust liability or have gone unchallenged by antitrust agencies (Gilo, 2000; Gilo, Moshe and Spiegel, 2006). As a matter of fact, Nain and Wang (2018) document that fewer than $1 \%$ of the minority acquisitions are challenged by the Federal Trade Commission (FTC) or the Department of Justice (DOJ), and even fewer are blocked outright. In the European Union (EU) and most other jurisdictions, antitrust authorities even have no competence to investigate such cases. ${ }^{5}$ As noted by Jovanovic and Wey (2014), in many merger cases the acquiring firm often owns a passive partial ownership stake in the target firm prior to the merger proposal. This two-step covert takeover strategy has the benefit of evading merger scrutiny when antitrust authorities often give the green light to non-controlling minority shareholdings, and of subsequently achieving the eventual goal of a full acquisition on the basis of increasing consumer surplus approved by antitrust authorities. Therefore, firms may view cross-ownership as a more attractive corporate strategy, further explaining why firms want to engage in cross-shareholdings. Our analysis thus suggests that competition authorities should adapt their current lenient approach towards minority shareholdings to a stricter regulation.

In the absence of any possible efficiency gains, passive cross-shareholdings result in a consumer surplus loss, and thus competition authorities should rule against them in accordance with a consumer surplus criterion. However, when competition authorities need to make the tradeoffs between the possible efficiency gains and the CS loss brought by cross-ownership, they should be cautious when ruling in the nonrenewable resource sector. As when the resource stock owned by each firm is small enough, cross-ownership may turn out to be less detrimental to consumers. Because a group of cross-owners will monopolize the market after the outsiders deplete their resource stocks. These cross-owners can raise the price much higher, which prevents the remaining resources from exhausting too fast and extends the duration of the resource that can be used. As the resource becomes increasingly scarce, the extended periods

\footnotetext{
${ }^{5}$ It should be noted that Articles 101 and/or 102 TFEU may apply to passive minority shareholdings in situations where there is evidence of an anticompetitive agreement or concerted practice among the investigated firms or the firms that are engaged in the acquisition of non-controlling stakes and/or one or more firms have a dominant position (Fotis and Zevgolis, 2016). But European Commission also acknowledged its limited ability to use these Articles to intervene against minority shareholdings in the 2013 Consultation Paper and therefore does not cover all types of anti-competitive minority interests.
} 
of the use of the resource partially offset the negative effect of the higher price on the consumer surplus.

The remainder of the paper is structured as follows. Section 2 presents both the static model in a generic industry and the dynamic model in the nonrenewable resource sector. Thereafter, Section 3 analyzes the profitability of cross-ownership. Section 4 conducts a welfare analysis. Finally, Section 5 concludes with the summary of our findings.

\section{The Model and Preliminary Analysis}

\subsection{The Static Model}

We consider an $n$-firm oligopolistic industry where firms compete à la Cournot. We assume the demand is linear and given by $p=a-b \sum_{j=1}^{n} q_{j}=a-b Q$, where $p$ is the market price charged and $q_{j}$ is the output produced by firm $j$. Marginal costs are constant and identical across all firms, denoted by $c$ with $a>c$. In an industry characterized by rival cross-shareholding, the aggregate profits of firm $j$, denoted by $\Pi_{j}$, include not just the stream of profits generated by the firm from its own operations, but also a share in its competitors' aggregate profits due to its direct and indirect ownership stakes in these firms. ${ }^{6}$ Following much of the literature (Flath, 1992; Dietzenbacher, Smid and Volkerink, 2000; Gilo, Moshe and Spiegel, 2006; Brito, Ribeiro and Vasconcelos, 2014), we thus model firm $j$ 's problem as

$$
\max _{q_{j} \geq 0} \Pi_{j}=\pi_{j}+\sum_{i \neq j} v_{j i} \Pi_{i}=(p-c) q_{j}+\sum_{i \neq j} v_{j i} \Pi_{i}
$$

where $\pi_{j}=(p-c) q_{j}$ denotes firm $j$ 's operating profit and $v_{j i} \geq 0(i \neq j)$ represents firm $j$ 's fractional shareholdings in firm $i$.

We consider a k-symmetric cross-ownership structure in which a subset of $k$ firms $(2 \leq k \leq$ $n$ ) engage in rival cross-shareholding and each firm has an equal silent financial interest in the other firms, i.e., $v_{i k}=v_{k i}=v$ for all $i, k$, while the remaining $n-k$ firms stay independent. We denote the set of firms as $J=\{1,2, \cdots, n\}$, indexed by $j$, and use the subsets $I=\{1,2, \cdots, k\}$, indexed by $i$ and $O=\{k+1, \cdots, n\}$, indexed by $o$, referring, respectively, to the insiders and

\footnotetext{
${ }^{6}$ The aggregate profits can be interpreted as the accounting profits or the taxable profits of firm $j$. For example, say, if the corporate tax rate is $20 \%$, then firm $j$ must pay the government a tax amount of $0.2 \Pi_{j}$.
} 
the outsiders to the cross-ownership. Let $\boldsymbol{\Pi}$ and $\boldsymbol{q}$ denote the $n \times 1$ vectors of net aggregate profits and outputs, respectively, $\boldsymbol{D}$ denote the $n \times n$ k-symmetric cross-shareholding matrix and $\boldsymbol{I}$ denote the identity matrix. We make the following assumption:

Assumption 1. Each firm seeks to maximize the value of its aggregate profits, but controls only its own production $q_{j}$, with rival shareholdings $v \leq \frac{1}{k}$, i.e., firms only have a silent financial interest or non-controlling minority stake in the rivals.

Several reasons may justify why we make this assumption. In practice, when a firm owns more than half of another firm, it will clearly obtain corporate control over the other firms' decision-making. In some cases, it might also obtain corporate control even if it owns less than half. If $v$ is sufficiently small, however, a firm would not likely obtain corporate control over others. In the corporate structure of a firm, the one with the highest shareholdings usually controls the firm. Thus it is reasonable to assume that all other firms hold a share smaller than the controlling shareholder, i.e., $v \leq 1 / k^{7,8}$ Secondly, horizontal mergers are subject to substantial antitrust scrutiny and are often opposed by antitrust authorities. Facing almost the same treatment as horizontal mergers, majority shareholdings or controlling minority

\footnotetext{
${ }^{7}$ Similar restriction is found in López and Vives (2019) where the upper bound for cross-shareholdings is $1 /(n-1)$ when $k=n$. We impose a stricter upper bound as it better reflects the corporate governance of a firm, for example, in a 5-firm oligopolistic industry, it makes little sense if all other 4 firms each holds a $1 / 4$ share of the firm while the firm can still make its own independent decision. Another problem with their proposal of allowing $v$ to be equal to $1 /(n-1)$ is that in that case, the determinant of the matrix $I-D$ will be zero, i.e., $(I-D)$ does not have an inverse. To prove this, notice that that the $n$ columns of the matrix $I-D$ are linearly dependent, i.e., there exists a non-zero row vector $\left(\alpha_{1}, \alpha_{2}, \ldots, \alpha_{n}\right)$ such that $(I-D) \times\left(\alpha_{1}, \alpha_{2}, \ldots, \alpha_{n}\right)^{T}$ is equal to the zero vector $(0,0, \ldots, 0)^{T}$ (where $T$ means "transposed"). One such vector is $(\lambda, \lambda, \lambda, \ldots, \lambda)$, with $\lambda \neq 0$. For example, if $k=n=5$, then when $v=1 /(5-1)=0.25$, the matrix $I-D$ is
}

$$
\left[\begin{array}{ccccc}
1 & -0.25 & -0.25 & -0.25 & -0.25 \\
-0.25 & 1 & -0.25 & -0.25 & -0.25 \\
-0.25 & -0.25 & 1 & -0.25 & -0.25 \\
-0.25 & -0.25 & -0.25 & 1 & -0.25 \\
-0.25 & -0.25 & -0.25 & -0.25 & 1
\end{array}\right]
$$

and, obviously, for any real number $\lambda$, direct calculation shows that

$$
\left[\begin{array}{ccccc}
1 & -0.25 & -0.25 & -0.25 & -0.25 \\
-0.25 & 1 & -0.25 & -0.25 & -0.25 \\
-0.25 & -0.25 & 1 & -0.25 & -0.25 \\
-0.25 & -0.25 & -0.25 & 1 & -0.25 \\
-0.25 & -0.25 & -0.25 & -0.25 & 1
\end{array}\right]\left[\begin{array}{c}
\lambda \\
\lambda \\
\lambda \\
\lambda \\
\lambda
\end{array}\right]=\left[\begin{array}{l}
0 \\
0 \\
0 \\
0 \\
0
\end{array}\right]
$$

\footnotetext{
${ }^{8}$ It should also be noted that under our assumption $v \leq 1 / k$, when $k=n$, the monopoly outcome can never be achieved with symmetric cross-ownership. To see this, in the standard Cournot model without cross-ownership, if all the $n$ firms act as a cartel, the industry output is $Q_{M}=\frac{a-c}{2 b}$, while the industry output for which all the firms engage in rival cross-shareholding is $Q_{v}=\frac{n-n(n-2) v}{n+1-(n(n-2)-1) v} \frac{a-c}{b}$. It can be easily shown that $Q_{v}<Q_{M}$ for all $v \in(0,1 / k]$.
} 
shareholdings fall directly under the scope of merger control in most jurisdictions. It is the non-controlling minority shareholdings or passive investments in rival firms that raises anticompetitive concerns, which may seem less pronounced as the competition among firms is not completely eliminated. For most jurisdictions, competition authorities have no legal substances to investigate such cases. Even though competition authorities in some countries (e.g., the US, Canada, the UK, and Germany) have the competence to review such cases, most transactions are either granted a de facto exemption from antitrust liability or have gone unchallenged by antitrust agencies (Gilo, 2000; Gilo, Moshe and Spiegel, 2006; Nain and Wang, 2018). Focusing on the non-controlling minority shareholdings may provide some policy implications about which appropriate minority shareholdings should be allowed without any further advance review.

The aggregate profit functions can be expressed as follows:

$$
\left[\begin{array}{c}
\Pi_{1} \\
\Pi_{2} \\
\vdots \\
\Pi_{k} \\
\Pi_{k+1} \\
\vdots \\
\Pi_{n}
\end{array}\right]=(p-c)\left[\begin{array}{c}
q_{1} \\
q_{2} \\
\vdots \\
q_{k} \\
q_{k+1} \\
\vdots \\
q_{n}
\end{array}\right]+\left[\begin{array}{ccccccc}
0 & v & \cdots & v & 0 & \cdots & 0 \\
v & 0 & \cdots & v & 0 & \cdots & 0 \\
\vdots & \vdots & \ddots & \vdots & \vdots & \ddots & \vdots \\
v & v & \cdots & 0 & 0 & \cdots & 0 \\
0 & 0 & \cdots & 0 & 0 & \cdots & 0 \\
\vdots & \vdots & \ddots & \vdots & \vdots & \ddots & \vdots \\
0 & 0 & \cdots & 0 & 0 & \cdots & 0
\end{array}\right]\left[\begin{array}{c}
\Pi_{1} \\
\Pi_{2} \\
\vdots \\
\Pi_{k} \\
\Pi_{k+1} \\
\vdots \\
\Pi_{n}
\end{array}\right]
$$

This set of $n$ equations implicitly defines the aggregate profit for each firm. Under Assumption 1, matrix $(\boldsymbol{I}-\boldsymbol{D})$ is invertible ${ }^{9}$, which implies that it is possible to solve for the aggregate

\footnotetext{
${ }^{9}$ This follows from the properties of "Dominant Diagonal Matrices" (see, e.g., Takayama (1985), Mathematical Economics, Cambridge University Press, page 381). According to Theorem 4.C.1 of that book, if an $n \times n$ matrix $A$ has a dominant diagonal, then $A^{-1}$ exists, where an $n \times n$ matrix $A$ is said to have a dominant diagonal if there exists positive numbers $d_{1}, d_{2}, \cdots, d_{n}$ such that, for each $j$, we have

$$
d_{j}\left|a_{j j}\right|>\sum_{i \neq j} d_{i}\left|a_{i j}\right|
$$
}

Clearly the matrix $\boldsymbol{I}-\boldsymbol{D}=A$ has a dominant diagonal because $a_{j j}=1$ and $\sum_{i \neq j} a_{i j}<1$. 
profit function: $\boldsymbol{\Pi}=(\boldsymbol{I}-\boldsymbol{D})^{-1}(p-c) \boldsymbol{q}$. Solving for $\boldsymbol{\Pi}$ yields

$$
\left[\begin{array}{c}
\Pi_{1} \\
\Pi_{2} \\
\vdots \\
\Pi_{k} \\
\Pi_{k+1} \\
\vdots \\
\Pi_{n}
\end{array}\right]=\frac{1}{\Delta}\left[\begin{array}{ccccccc}
1-(k-2) v & v & \cdots & v & 0 & \cdots & 0 \\
v & 1-(k-2) v & \cdots & v & 0 & \cdots & 0 \\
\vdots & \vdots & \ddots & \vdots & \vdots & \ddots & \vdots \\
v & v & \cdots & 1-(k-2) v & 0 & \cdots & 0 \\
0 & 0 & \cdots & 0 & \Delta & \cdots & 0 \\
\vdots & \vdots & \ddots & \vdots & \vdots & \ddots & \vdots \\
0 & 0 & \cdots & 0 & 0 & \cdots & \Delta
\end{array}\right]\left[\begin{array}{c}
(a-c-b Q) q_{1} \\
(a-c-b Q) q_{2} \\
\vdots \\
(a-c-b Q) q_{k} \\
(a-c-b Q) q_{k+1} \\
\vdots \\
(a-c-b Q) q_{n}
\end{array}\right]
$$

where $\Delta=1-(k-2) v-(k-1) v^{2}$. Let's write $Q=q_{j}+Q_{-j}$. Then for a typical firm $i \in I$, the aggregate profit function is

$$
\Pi_{i}=\frac{a-c-b Q_{-i}-b q_{i}}{\Delta}\left[(1-(k-2) v) q_{i}+v \sum_{k \in I \backslash i} q_{k}\right]
$$

while for a typical firm $o \in O$, the aggregate profit function is

$$
\Pi_{o}=\left(a-b Q_{-o}-b q_{o}-c\right) q_{o}
$$

Firm $j$ takes other firms' production $Q_{-j}$ as given and chooses $q_{j}$ to maximize its aggregate profit. The first order conditions are

$$
\begin{gathered}
(1-(k-2) v)\left(a-c-b Q_{-i}-b q_{i}\right)-b\left[(1-(k-2) v) q_{i}+v \sum_{k \in I \backslash i} q_{k}\right]=0 \\
a-c-2 b q_{o}-b Q_{-o}=0
\end{gathered}
$$

Exploiting symmetry, the interior solution ${ }^{10}$ yields the static Cournot equilibrium outputs:

$$
q_{i}^{v}=\frac{(2-k) v+1}{\left(k+n+1-k^{2}\right) v+n+1} \frac{a-c}{b}, \quad q_{o}^{v}=\frac{1+v}{\left(k+n+1-k^{2}\right) v+n+1} \frac{a-c}{b}
$$

\footnotetext{
${ }^{10}$ Note that the denominator is positive because we have imposed the restriction that $v \leq 1 / k$.

$\left(k+n+1-k^{2}\right) v+n+1=n+1+(n+1) v-k(k-1) v \geq n+1+v(n+1)-k+1>0$
} 
Thus, the equilibrium industry output is

$$
Q_{v}=k q_{i}^{v}+(n-k) q_{o}^{v}=\frac{\left(-k^{2}+n+k\right) v+n}{\left(k+n+1-k^{2}\right) v+n+1} \frac{a-c}{b}
$$

\subsection{The Dynamic Model}

The above model, however, cannot apply directly to the exhaustible resource sector, as the specificity of a nonrenewable resource (i.e., current extraction goes at the cost of future extraction) makes it inherently a dynamic problem. We thus need to modify the static model slightly to incorporate this dynamic feature. In particular, we consider an exhaustible resource industry involving $n$ firms with the same initial stock endowments $S_{i 0}=S$ and the same marginal cost of production $c$. Firms are oligopolists in the resource market where they compete à la Cournot. Let $q_{j}(t) \geq 0$ denote the extraction rate at time $t$ for firm $j$. Demand for resource is stationary and linear with a choke price $a>c$, so that the inverse demand at time $t \geq 0$ for the extracted resource is given by $p(t)=a-b Q(t)=a-b \sum_{j=1}^{n} q_{j}(t)$. In an industry characterized by rival cross-shareholdings, the aggregate profits of firm $j$ at time $t$ is as follows:

$$
\Pi_{j}(t)=\pi_{j}(t)+\sum_{i \neq j} v_{j i} \Pi_{i}(t)=(p(t)-c) q_{j}(t)+\sum_{i \neq j} v_{j i} \Pi_{i}(t)
$$

Each firm $j$ takes the supply paths of all other firms as given and maximizes the discounted sum of the aggregate profits, which consists of its operating profit and the share of profits obtained through ownership interests in other firms, subject to its resource constraint:

$$
\begin{gathered}
\max _{q_{j}(t) \geq 0} \int_{0}^{\infty} e^{-r t}\left[(a-b Q(t)-c) q_{j}(t)+\sum_{i \neq j} v_{j i} \Pi_{i}(t)\right] d t \\
\text { s.t. } \quad \int_{0}^{\infty} q_{j}(t) d t \leq S_{0 j}
\end{gathered}
$$

We consider the k-symmetric cross-ownership structure as in the static model and make a similar assumption:

Assumption 2. Each firm $j$ seeks to maximize the discounted sum of the value of its aggregate profits, including returns on any shares held in rivals, but controls only its own production $q_{j}(t)$ with $v \leq 1 / k$ for all $i, k$, i.e., firms only have a silent financial interest or non-controlling 
minority stake in the rivals.

Under Assumption 2, it is possible to solve for the aggregate profit equation at each time $t$, and thus the problem of all firms can be reformulated as

$$
\begin{aligned}
& \max _{\boldsymbol{q}(t) \geq 0} \int_{0}^{\infty} e^{-r t}\left(\left[\begin{array}{ccccccc}
1 & -v & \cdots & -v & 0 & \cdots & 0 \\
-v & 1 & \cdots & -v & 0 & \cdots & 0 \\
\vdots & \vdots & \ddots & \vdots & \vdots & \ddots & \vdots \\
-v & -v & \cdots & 1 & 0 & \cdots & 0 \\
0 & 0 & \cdots & 0 & 1 & \cdots & 0 \\
\vdots & \vdots & \ddots & \vdots & \vdots & \ddots & \vdots \\
0 & 0 & \cdots & 0 & 0 & \cdots & 1
\end{array}\right]^{-1}\left[\begin{array}{c}
(a-c-b Q(t)) q_{1}(t) \\
(a-c-b Q(t)) q_{2}(t) \\
\vdots \\
(a-c-b Q(t)) q_{k}(t) \\
(a-c-b Q(t)) q_{k+1}(t) \\
\vdots \\
(a-c-b Q(t)) q_{n}(t)
\end{array}\right]\right) d t \\
& \text { s.t. } \quad\left[\begin{array}{cc}
\int_{0}^{\infty} & q_{1}(t) d t \\
\int_{0}^{\infty} & q_{2}(t) d t \\
\vdots \\
\int_{0}^{\infty} & q_{n}(t) d t
\end{array}\right] \leq\left[\begin{array}{c}
S_{01} \\
S_{02} \\
\vdots \\
S_{0 n}
\end{array}\right]
\end{aligned}
$$

Let's write $Q(t)=q_{j}(t)+Q_{-j}(t)$. Then for a typical firm $i \in I$,

$$
\begin{gathered}
\max _{q_{i}(t) \geq 0} \int_{0}^{\infty} e^{-r t}\left[\frac{1}{1-(k-2) v-(k-1) v^{2}}\left((1-(k-2) v) q_{i}+v \sum_{k \in I \backslash i} q_{k}\right)\left(a-c-b Q_{-i}-b q_{i}\right)\right] d t \\
\text { s.t. } \quad \int_{0}^{\infty} q_{i}(t) d t \leq S_{0 i}
\end{gathered}
$$

while for a typical firm $o \in O$,

$$
\begin{gathered}
\max _{q_{o}(t) \geq 0} \int_{0}^{\infty} e^{-r t}\left[\left(a-b Q_{-o}-b q_{o}-c\right) q_{o}\right] d t \\
\text { s.t. } \quad \int_{0}^{\infty} q_{o}(t) d t \leq S_{0 o}
\end{gathered}
$$

We characterize an open-loop Nash-Cournot cross-ownership equilibrium (OL-NCOE) of this game. More precisely,

Definition 1 (Open-loop Nash-Cournot Cross-ownership Equilibrium (OL-NCOE)). A n-tuple vector of extraction paths $\boldsymbol{q}=\left(q_{1}, q_{2}, \cdots, q_{k}, q_{k+1}, \cdots, q_{n}\right)$ with $q(t) \geq 0$ for all $t \geq 0$ is an 
open-loop Nash-Cournot cross-ownership equilibrium if

(i) every extraction path is admissible and satisfies the corresponding resource constraint,

(ii) for all $i \in I$,

$$
\begin{aligned}
& \int_{0}^{\infty} e^{-r t}\left[\frac{1}{1-(k-2) v-(k-1) v^{2}}\left((1-(k-2) v) q_{i}+v \sum_{k \in I \backslash i} q_{k}\right)\left(a-c-b Q_{-i}-b q_{i}\right)\right] d t \\
\geq & \int_{0}^{\infty} e^{-r t}\left[\frac{1}{1-(k-2) v-(k-1) v^{2}}\left((1-(k-2) v) q_{l}+v \sum_{k \in I \backslash l} q_{k}\right)\left(a-c-b Q_{-i}-b q_{l}\right)\right] d t
\end{aligned}
$$

for all $q_{l}$ satisfying the resource constraint, and

(iii) for all $o \in O$,

$$
\begin{aligned}
& \int_{0}^{\infty} e^{-r t}\left[\left(a-b Q_{-o}-b q_{o}-c\right) q_{o}\right] d t \\
\geq & \int_{0}^{\infty} e^{-r t}\left[\left(a-b Q_{-o}-b q_{m}-c\right) q_{m}\right] d t
\end{aligned}
$$

for all $q_{m}$ satisfying the resource constraint.

We now proceed to characterize an OL-NCOE of the above-defined game. We first show that all firms exhaust their stocks in finite time. Let $T_{i}$ and $T_{o}$ denote the time at which firm $i \in I$ and firm $o \in O$ deplete their stocks. It can be shown that for all $0<v \leq 1 / k$, we have $T_{i}>T_{o}$. The equilibrium then consists of two phases: phase I from date 0 to $T_{o}$, and phase II from $T_{o}$ to $T_{i}$. During phase $\mathrm{I}$, the extraction of all the $n$ firms is positive until $T_{o}$, where the extraction and the stock of firms $o \in O$ vanish. During phase II, only firms $i \in I$ still own a positive stock, until $T_{i}$ where the extraction and the stock of these remaining firms vanish. We denote by $q_{i}$ and $q_{o}$ the extraction paths of firm $i \in I$ and firm $o \in O$ respectively.

Proposition 1. Assume that the initial stocks of all firms are equal, i.e., $S_{0 j}=S$, then the $n$-tuple vector $\boldsymbol{q}^{e q}$ where $q_{j}^{e q}=q_{i}$ when $j=1,2, \cdots, k$ and $q_{j}^{e q}=q_{o}$ when $j=k+1, \cdots, n$ 
constitutes an OL-NCOE.

$q_{i}(t)= \begin{cases}\frac{(1-(k-2) v)(a-c)\left[1+k+(1-k(k-2)) v-\left(\left(k+n+1-k^{2}\right) v+n+1\right) e^{\left.r^{r\left(t-T_{i}\right)}+(n-k)(1+v) e^{r\left(t-T_{o}\right)}\right]}\right.}{\left(\left(k+n+1-k^{2}\right) v+n+1\right)[1+k+(1-k(k-2)) v] b} & \text { for } 0 \leq t \leq T_{o} \\ \frac{(1-(k-2) v)(a-c)}{[1+k+(1-k(k-2)) v] b}\left[1-e^{r\left(t-T_{i}\right)}\right] & \text { for } T_{o} \leq t \leq T_{i} \\ 0 & \text { for } t \geq T_{i}\end{cases}$

$q_{o}(t)= \begin{cases}\frac{(a-c)(1+v)}{\left(\left(k+n+1-k^{2}\right) v+n+1\right) b}\left[1-e^{r\left(t-T_{o}\right)}\right] & \text { for } 0 \leq t \leq T_{o} \\ 0 & \text { for } t \geq T_{o}\end{cases}$

where $T_{i}$ and $T_{o}$ are the unique solutions to

$$
\int_{0}^{T_{i}} q_{i}(t) d t=S, \quad \int_{0}^{T_{o}} q_{o}(t) d t=S
$$

Proof. We characterize the OL-NCOE by using optimal control theory. The current value Hamiltonian associated with the problem of a typical firm $i \in I$ is given by $H_{i}\left(q_{i}, Q_{-i}, \lambda_{i}, t\right)=\frac{1}{1-(k-2) v-(k-1) v^{2}}\left((1-(k-2) v) q_{i}+v \sum_{k \in I \backslash i} q_{k}\right)\left(a-c-b Q_{-i}-b q_{i}\right)-\lambda_{i} q_{i}$, while that for a typical firm $o \in O$ is

$$
H_{o}\left(q_{o}, Q_{-o}, \lambda_{o}, t\right)=\left(a-b Q_{-o}-b q_{o}-c\right) q_{o}-\lambda_{o} q_{o}
$$

Exploiting symmetry, the maximum principle yields the interior solution

$$
(1-(k-2) v)(a-c)-[1+k+(1-k(k-2)) v] b q_{i}-(1-(k-2) v)(n-k) b q_{o}=\lambda_{i}\left(1-(k-2) v-(k-1) v^{2}\right)
$$

$$
a-c-(n-k+1) b q_{o}-b k q_{i}=\lambda_{o}
$$


for $i=1,2, \cdots, k$ and $o=k+1, \cdots, n$, with

$$
\begin{aligned}
& \frac{d \lambda_{i}}{d t}=r \lambda_{i} \\
& \frac{d \lambda_{o}}{d t}=r \lambda_{o}
\end{aligned}
$$

Solving for $\left(q_{i}, q_{o}\right)$ from (6) and (7), then we get

$$
\begin{gathered}
q_{i}(t)=\frac{(1-(k-2) v)(a-c)-\left(1-(k-2) v-(k-1) v^{2}\right)(n-k+1) \lambda_{i}+(1-(k-2) v)(n-k) \lambda_{o}}{\left(\left(k+n+1-k^{2}\right) v+n+1\right) b} \\
q_{o}(t)=\frac{(1+v)(a-c)+\left(1-(k-2) v-(k-1) v^{2}\right) k \lambda_{i}-[1+k+(1-k(k-2)) v] \lambda_{o}}{\left(\left(k+n+1-k^{2}\right) v+n+1\right) b}
\end{gathered}
$$

During the second phase where only firms $i \in I$ extract a positive quantity, the maximum principle yields

$$
(1-(k-2) v)(a-c)-[1+k+(1-k(k-2)) v] b q_{i}=\lambda_{i}\left(1-(k-2) v-(k-1) v^{2}\right)
$$

with

$$
\frac{d \lambda_{i}}{d t}=r \lambda_{i}
$$

Solving for $q_{i}$ from (12), we obtain

$$
q_{i}(t)=\frac{(1-(k-2) v)(a-c)-\left(1-(k-2) v-(k-1) v^{2}\right) \lambda_{i}}{[1+k+(1-k(k-2)) v] b}
$$

The terminal dates $T_{i}$ and $T_{o}$ are endogenous and determined by

$$
H_{i}\left(q_{i}\left(T_{i}\right), q_{-i}\left(T_{i}\right), \lambda_{i}\left(T_{i}\right), T_{i}\right)=0
$$

for $i \in I$ and

$$
H_{o}\left(q_{o}\left(T_{o}\right), q_{-o}\left(T_{o}\right), \lambda_{o}\left(T_{o}\right), T_{o}\right)=0
$$


for $o \in O$. These terminal conditions along with the maximum principle imply that

$$
q_{i}\left(T_{i}\right)=0, \quad q_{o}\left(T_{o}\right)=0
$$

From (8),(9) and (13) and continuity of the costate variable $\lambda_{i}$ at $T_{o}$, we have

$$
\begin{aligned}
& \lambda_{i}=\lambda_{i 0} e^{r t} \quad \forall t \in\left[0, T_{i}\right] \\
& \lambda_{o}=\lambda_{o 0} e^{r t} \quad \forall t \in\left[0, T_{o}\right]
\end{aligned}
$$

where $\lambda_{i 0}$ and $\lambda_{o 0}$ are determined using conditions (15) along with (14) and (11). From (14), we have

$$
q_{i}\left(T_{i}\right)=\frac{(1-(k-2) v)(a-c)-\left(1-(k-2) v-(k-1) v^{2}\right) \lambda_{i 0} e^{r T_{i}}}{[1+k+(1-k(k-2)) v] b}=0,
$$

that is,

$$
\lambda_{i 0}=(a-c)(1-(k-2) v)\left(1-(k-2) v-(k-1) v^{2}\right)^{-1} e^{-r T_{i}}
$$

and

$$
\lambda_{i}=\lambda_{i 0} e^{r t}=(a-c)(1-(k-2) v)\left(1-(k-2) v-(k-1) v^{2}\right)^{-1} e^{r\left(t-T_{i}\right)}
$$

From (11), we have

$$
q_{o}\left(T_{o}\right)=\frac{(1+v)(a-c)+\left(1-(k-2) v-(k-1) v^{2}\right) k \lambda_{i}\left(T_{o}\right)-[1+k+(1-k(k-2)) v] \lambda_{o}\left(T_{o}\right)}{\left(\left(k+n+1-k^{2}\right) v+n+1\right) b}=0
$$

that is,

$$
\lambda_{o 0}=\frac{a-c}{1+k+(1-k(k-2)) v}\left[(1+v) e^{-r T_{o}}+k(1-(k-2) v) e^{-r T_{i}}\right]
$$

and

$$
\lambda_{o}=\lambda_{o 0} e^{r t}=\frac{a-c}{1+k+(1-k(k-2)) v}\left[(1+v) e^{r\left(t-T_{o}\right)}+k(1-(k-2) v) e^{r\left(t-T_{i}\right)}\right]
$$


Substituting (18) and (19) into (10), (11) and (14) yields the Phase $\mathrm{I}\left(0 \leq t \leq T_{o}\right)$ and Phase II $\left(T_{o} \leq t \leq T_{i}\right)$ equilibrium supply paths of all the firms as presented in (3) and (4). These equilibrium paths are determined as functions of the terminal times $T_{i}$ and $T_{o}$, which are determined from the resource constraint conditions, i.e.,(5). It can be shown that such a non-linear system in $\left(T_{i}, T_{o}\right)$ admits a unique solution, with $T_{i} \geq T_{o}$. A full proof is provided in the following.

The terminal dates $T_{i}$ and $T_{o}$ are determined from the resource constraint conditions. More specifically,

$\int_{0}^{T_{o}} \frac{(1-(k-2) v)(a-c) \cdot A}{\left(\left(k+n+1-k^{2}\right) v+n+1\right)[1+k+(1-k(k-2)) v] b} d t+\int_{T_{o}}^{T_{i}} \frac{(1-(k-2) v)(a-c) \cdot B}{[1+k+(1-k(k-2)) v] b} d t=S_{0 i}$

where

$$
\begin{gathered}
A=\left[1+k+(1-k(k-2)) v-\left(\left(k+n+1-k^{2}\right) v+n+1\right) e^{r\left(t-T_{i}\right)}+(n-k)(1+v) e^{r\left(t-T_{o}\right)}\right] \\
B=\left[1-e^{r\left(t-T_{i}\right)}\right]
\end{gathered}
$$

and

$$
\int_{0}^{T_{o}} \frac{(a-c)(1+v)}{\left(\left(k+n+1-k^{2}\right) v+n+1\right) b}\left[1-e^{r\left(t-T_{o}\right)}\right] d t=S_{0 o}
$$

From (20), we have

$$
\begin{gathered}
\frac{(1-(k-2) v)}{[1+k+(1-k(k-2)) v]}\left[\left(\left(k+n+1-k^{2}\right) v+n+1\right)\left(e^{-r T_{i}}+r T_{i}-1\right)-(n-k)(1+v)\left(e^{-r T_{o}}+r T_{o}-1\right)\right] \\
=\frac{\left(\left(k+n+1-k^{2}\right) v+n+1\right) b r S_{0 i}}{(a-c)}
\end{gathered}
$$

From (21), we have

$$
(1+v)\left(e^{-r T_{o}}+r T_{o}-1\right)=\frac{\left(\left(k+n+1-k^{2}\right) v+n+1\right) b r S_{0 o}}{(a-c)}
$$


Same resource endowments $S_{0 i}=S_{0 o}=S$ yields

$$
\begin{gathered}
\frac{(1-(k-2) v)}{[1+k+(1-k(k-2)) v]}\left[\left(\left(k+n+1-k^{2}\right) v+n+1\right)\left(e^{-r T_{i}}+r T_{i}-1\right)-(n-k)(1+v)\left(e^{-r T_{o}}+r T_{o}-1\right)\right] \\
=(1+v)\left(e^{-r T_{o}}+r T_{o}-1\right)
\end{gathered}
$$

or

$$
(1-(k-2) v)\left(\left(k+n+1-k^{2}\right) v+n+1\right)\left(e^{-r T_{i}}+r T_{i}-1\right)=(1+v)((1-n(k-2)) v+n+1)\left(e^{-r T_{o}}+r T_{o}-1\right)
$$

Since

$$
(1-(k-2) v)\left(\left(k+n+1-k^{2}\right) v+n+1\right)<(1+v)((1-n(k-2)) v+n+1) \quad \forall v \in\left(0, \frac{1}{k}\right]
$$

then we must have

$$
f\left(T_{i}\right)=e^{-r T_{i}}+r T_{i}-1>f\left(T_{o}\right)=e^{-r T_{o}}+r T_{o}-1 \quad \text { for } T_{i}>T_{o}
$$

In other words, we need to show that $f(T)=e^{-r T}+r T-1$ is an increasing function. Indeed,

$$
f^{\prime}(T)=-r e^{-r T}+r=r\left(1-e^{-r T}\right)>0
$$

Thus we have finished our proof.

\section{Profitability of Cross-ownership}

In this section, we exploit the characterization of both the static Cournot equilibrium and the OL-NCOE in the above-defined game to investigate the profitability of the k-symmetric cross-ownership in the industry. We define the profitability of cross-ownership in the static case as the difference between the equilibrium operating profits with and without cross-ownership, and in the dynamic case as the difference between the equilibrium discounted sum of operating profits with and without cross-ownership. ${ }^{11}$ We first focus on the static case for a generic

\footnotetext{
${ }^{11}$ Here we use the operating profits $\left(\pi_{j}\right)$ instead of the aggregate profits or accounting profits $\left(\Pi_{j}\right)$ to compare with the case of a standard Cournot model. This is the usual distinction we make about the economic profits
} 
industry and formally define our findings as the cross-ownership paradox, analogous to the merger paradox. We then compare cross-ownership with horizontal merger and provide some explanations as to why firms want to engage in cross-shareholdings instead of a full merger. Next, we move to focus on the exhaustible sector. Specifically, we numerically examine the profitability under different cross-ownership structures and show that a k-symmetric cross-ownership can be profitable even when the participation ratio $\frac{k}{n}$ is less than or equal to $\frac{1}{2}\left(\frac{n+1}{n}\right)$ and is always profitable when the participation ratio $\frac{k}{n}$ is greater than $\frac{1}{2}\left(\frac{n+1}{n}\right)$, provided that the resource stock owned by each firm is small enough for any levels of cross-ownership. Finally, we examine the impact of cross-ownership on the speed of extraction of the nonrenewable resource through numerical simulations.

\subsection{Profitability in Static Case}

The equilibrium operating profit for a typical firm $i$ that engage in $\mathrm{k}$-symmetric cross-ownership is given by

$$
\pi_{v}(k, n, v)=\left(a-b Q_{v}-c\right) q_{i}^{v}=\frac{(1+v)(1-(k-2) v)}{\left(\left(k+n+1-k^{2}\right) v+n+1\right)^{2}} \frac{(a-c)^{2}}{b}
$$

while that for a typical firm in the standard Cournot model without cross-ownership is

$$
\pi_{c}=\pi_{v}(k, n, 0)=\frac{1}{(n+1)^{2}} \frac{(a-c)^{2}}{b}
$$

A k-symmetric cross-ownership is profitable if

$G(k, n, v)=\pi_{v}(k, n, v)-\pi_{v}(k, n, 0)=\frac{\left[(n+1)(v+1)(2 k-n-1)-k^{2} v(k-1)\right] v(k-1)}{\left(\left(k+n+1-k^{2}\right) v+n+1\right)^{2}(n+1)^{2}}\left[\frac{(a-c)^{2}}{b}\right]>0$

We summarize in Proposition 2 the profitability of a $k$-symmetric cross ownership in the static case.

Proposition 2. For any $2 \leq k \leq n$ and $0<v \leq \frac{1}{k}$, a $k$-symmetric cross-ownership is never and accounting profits. 
profitable for Cournot competitors if the participation ratio $y=\frac{k}{n} \leq \frac{1}{2}\left(\frac{n+1}{n}\right)$. However, as long as $y=\frac{k}{n}>\frac{1}{2}\left(\frac{n+1}{n}\right)$ holds, any value of $\beta$ defined as $\beta=v(k-1) \in\left(0, \frac{k-1}{k}\right]$ in the interval $\left(0, \beta_{\max }\right]$ will ensure a positive profitability, where $\beta_{\max }=\frac{k-1}{k}$ if $(k-1) k^{2}-(n+1)(2 k-n-1) \leq 0$, and otherwise,

$$
\beta_{\max }= \begin{cases}\frac{(n+1)(2 k-n-1)(k-1)}{(k-1) k^{2}-(n+1)(2 k-n-1)}, & \text { if } \frac{(n+1)(2 k-n-1)(k-1)}{(k-1) k^{2}-(n+1)(2 k-n-1)}<\frac{k-1}{k} \\ \frac{k-1}{k}, & \text { if } \frac{(n+1)(2 k-n-1)(k-1)}{(k-1) k^{2}-(n+1)(2 k-n-1)} \geq \frac{k-1}{k}\end{cases}
$$

Proof. Let $y=\frac{k}{n}$, then for $2 \leq k \leq n, \frac{2}{n} \leq y \leq 1$. We can rewrite $G$ as

$$
G(k, n, v)=\frac{\left[(n+1)(v+1)(2 y n-n-1)-y^{2} n^{2} v(y n-1)\right] v(k-1)}{\left(\left(k+n+1-k^{2}\right) v+n+1\right)^{2}(n+1)^{2}}\left[\frac{(a-c)^{2}}{b}\right]
$$

Then, when $v>0$, we will have $G>0$ if and only if

$$
(n+1)(v+1)(2 y n-n-1)-y^{2} n^{2} v(y n-1)>0
$$

Denote

$$
v=\frac{\beta}{k-1}=\frac{\beta}{y n-1}, \quad \text { where } 0<\beta \leq \frac{k-1}{k}
$$

Then

$$
(n+1)(2 y n-n-1)\left(\frac{\beta+y n-1}{y n-1}\right)-y^{2} n^{2} \beta>0
$$

Since $2 \leq k=y n \leq n$, clearly, $G>0$ if and only if

$$
J \equiv(n+1)(2 y n-n-1)(\beta+y n-1)+(1-y n) y^{2} n^{2} \beta>0
$$

Suppose $y \leq \frac{1}{2}\left(\frac{n+1}{n}\right)$. Then $(2 y n-n-1) \leq 0$ and thus the first term on the RHS of equation (22) is negative or zero, and the second term on the RHS of equation (22) is negative (as $y n \geq 2$ ), and thus we have $J<0$. Therefore, for $J$ to be positive, it is necessary that

$$
y>\frac{1}{2}\left(\frac{n+1}{n}\right) .
$$


So, suppose $y>\frac{1}{2}\left(\frac{n+1}{n}\right)$, then $(2 y n-n-1)>0$ and thus the first term on the RHS of eq $(22)$ is positive and the second term is negative (as $y n \geq 2$ ). Therefore if $\beta$ is close to 0 , we have $J>0$. Then, given that $y>\frac{1}{2}\left(\frac{n+1}{n}\right)$, the subset $\beta$ such that $J>0$ is defined by the condition

$$
(n+1)(2 y n-n-1)(y n-1)>\beta\left[(y n-1) y^{2} n^{2}-(n+1)(2 y n-n-1)\right]
$$

or

$$
(n+1)(2 k-n-1)(k-1)>\beta\left[(k-1) k^{2}-(n+1)(2 k-n-1)\right]
$$

Note that the term $[\cdots]$ on the RHS of equation (23) may be positive or negative. If it is negative, then $J>0$ for all $\beta \in\left(0, \frac{k-1}{k}\right]$. If it is positive, then $J>0$ for all $\beta$ in $\left(0, \beta_{\max }\right]$, where

$$
\beta_{\max }=\left\{\begin{array}{lll}
\frac{(n+1)(2 k-n-1)(k-1)}{(k-1) k^{2}-(n+1)(2 k-n-1)}, & \text { if } & \frac{(n+1)(2 k-n-1)(k-1)}{(k-1) k^{2}-(n+1)(2 k-n-1)}<\frac{k-1}{k} \\
\frac{k-1}{k}, & \text { if } & \frac{(n+1)(2 k-n-1)(k-1)}{(k-1) k^{2}-(n+1)(2 k-n-1)} \geq \frac{k-1}{k}
\end{array}\right.
$$

This result seems surprising as one would naturally think it should be always profitable for firms to participate in cross-ownership. We thus define this result as a cross-ownership paradox, analogous to the merger paradox. A closer look at the threshold cross-ownership participation ratio $\frac{1}{2}\left(\frac{n+1}{n}\right)$ indicates that firms can never profit from cross-shareholdings if less than half of the firms in the industry participate. This 50-percent benchmark has also been addressed in Levin (1990)'s analysis of horizontal mergers, which finds that, under quite general conditions, if a group of firms with less than 50 percent of market output considers a horizontal merger, then any contraction of output by the merged group will cut profits below the level obtained by only reallocating their premerger output. However, our threshold includes ratios beyond only 50 percent, and crucially depends on both $k$ and $n$. For example, when $k=2$ and $n=3$ $(y=66.7 \%), k=3$ and $n=5(y=60 \%), k=4$ and $n=7(y=57.1 \%)$, firms will also find any levels of cross-shareholdings unprofitable. The second part of the cross-ownership paradox posits a large range of cross-shareholdings for which a k-symmetric cross-ownership can be profitable when the participation ratio $y=\frac{k}{n}>\frac{1}{2}\left(\frac{n+1}{n}\right)$. As it may seem complicated at first, we illustrate it using several examples below.

Example 1. Consider $n=10$, and let $k$ be the smallest integer that is bigger than or equal to 
$\frac{1}{2}(10+1)$, i.e., $k=6$. Then $y=\frac{k}{n}=0.6$, and

$$
(k-1) k^{2}-(n+1)(2 k-n-1)=(6-1)(36)-(10+1)(12-10-1)=169>0
$$

Then

$$
\beta_{\max }=\frac{(10+1)(12-10-1)(6-1)}{169}=0.32544<\frac{k-1}{k}=\frac{5}{6}=0.83333
$$

Thus cross-ownership with $n=10$ and $k=6$ is profitable if and only if

$$
v \leq v_{\max }=\frac{\beta_{\max }}{k-1}=\frac{0.32544}{6-1}=0.065088
$$

Example 1 shows that with $n=10$ and $k=6$, cross-ownership is profitable provided that each of the 6 firms holds no more than $6.5 \%$ of the shares of any other firm. (See also Figure 7b.)

Example 2. Consider $n=9, k=6$ and $y=\frac{2}{3}=0.67$. Then

$$
(k-1) k^{2}-(n+1)(2 k-n-1)=(6-1)(36)-(9+1)(12-9-1)=160>0
$$

Then

$$
\beta_{\max }=\frac{(9+1)(12-9-1)(6-1)}{160}=0.625<\frac{k-1}{k}=\frac{5}{6}=0.83333
$$

Thus cross-ownership with $n=9$ and $k=6$ is profitable if and only if:

$$
v \leq v_{\max }=\frac{\beta_{\max }}{k-1}=\frac{0.625}{6-1}=0.125
$$

Example 2 shows that with $n=9$ and $k=6$, cross-ownership is profitable provided that each of the 6 firms holds no more than $12.5 \%$ of the shares of any other firm. (See also Figure 6b.)

Example 3. Consider $n=8, k=6$ and $y=\frac{3}{4}=0.75$. Then

$$
(k-1) k^{2}-(n+1)(2 k-n-1)=(6-1)(36)-(8+1)(12-8-1)=153>0
$$

Then

$$
\beta=\frac{(8+1)(12-8-1)(6-1)}{153}=0.88235>\frac{k-1}{k}=\frac{5}{6}=0.83333
$$


Thus

$$
\beta_{\max }=\frac{k-1}{k}=0.83333
$$

and cross-ownership with $n=8$ and $k=6$ is profitable if and only if:

$$
v \leq v_{\max }=\frac{1}{k}=0.167
$$

Example 3 shows that with $n=8$ and $k=6$, cross-ownership is always profitable for any $v \in(0,1 / k]$. (See also Figure $5 b$.

Throughout Example 1-3, we observe the following result.

Result 1. Under Cournot competition, when the participation ratio $y=\frac{k}{n}>\frac{1}{2}\left(\frac{n+1}{n}\right)$, a k-symmetric cross-ownership is more likely to be profitable with lower levels of shareholdings for a lower participation ratio.

The intuition behind this result is that a larger shareholding by the firms that engage in the symmetric cross-ownership will induce them to reduce output by more, but this triggers a more aggressive response by the outsiders in terms of strategic substitutes in Cournot competition. The increase in both the number of outsiders and the output of the outsiders more than offsets the benefit the cross-owners can receive from their reduction of output, thereby reducing the profitability of cross-ownership. This result has shed light on the differences between cross-ownership and horizontal mergers, possibly explaining why firms may prefer to participate in cross-ownership than in a horizontal merger. For example, when $n=10$ and $k=6$, the profitability of a k-symmetric cross-ownership is positive provided that each of the 6 firms holds no more than $6.5 \%$ of the non-controlling minority shares of any other firm, while that of a horizontal merger of 6 firms is negative.

These findings also raise some practical considerations from a company's corporate strategy viewpoint. Not only is it more profitable to participate in the cross-ownership than a horizontal merger, more importantly, it constitutes a "smart" way to avoid the possible legal challenges. In the US, partial cross-ownership arrangements are most often examined under Section 7 of the Clayton Act and the Hart-Scott-Rodino (HSR) Act. ${ }^{12}$ While Section 7 of the Clayton

\footnotetext{
${ }^{12}$ Acquisitions of voting securities can be also challenged under Section 1 of the Sherman Act, which prohibits contracts, combinations, or conspiracies in restraint of trade, but a plaintiff challenging an acquisition under Section 1 carries the burden of proving an actual anticompetitive effect through a restraint of trade, as well as concerted action.
} 
Act covers the acquisition of "any part" of the stock of another company, it also "shall not apply to persons purchasing such stock solely for investment". The ambiguity in the statutory language has left courts struggling to evaluate partial stock acquisitions and unable to set forth any clear guidelines or parameters as to what the "safe" shareholdings are. Perhaps the HSR Act, which exempts from reporting requirements acquisitions solely for purposes of investment when the securities acquired or held do not exceed $10 \%$ of the outstanding voting securities of the issuer, provides some clarity. But the law remains highly uncertain and provides very little guidance for antitrust practitioners trying to assess the antitrust risk of partial stock acquisitions (O'Brien and Salop, 2000). As a result, antitrust authorities have adopted a lenient approach toward passive investments. As a matter of fact, Nain and Wang (2018) document that fewer than $1 \%$ of the minority acquisitions are challenged by FTC or DOJ, and even fewer are blocked. In the EU and most other jurisdictions, however, antitrust authorities have no competence to investigate such cases. As noted by Jovanovic and Wey (2014), in many merger cases, the acquiring firm often owns a passive partial ownership stake in the target firm prior to the merger proposal. They show that antitrust authorities, which do not account for passive partial ownership acquisitions, create incentives among firms to engage in sneaky takeovers, which proceed in two steps. First, the acquiring firm abstains from proposing a full acquisition, as this would harm consumers. Rather, it strategically acquires a passive partial ownership, which often goes unnoticed or unchallenged by the antitrust authorities. Second, the acquiring firm proposes a full takeover, which can then be viewed as consumer surplus increasing and accepted by the antitrust authorities. The consumer surplus increases because passive partial ownership reduces the necessary minimal synergy level that leaves consumer surplus unchanged by a merger, thus relaxing the synergy requirement for a merger to increase consumer surplus. As a result, a larger set of such synergies would be supported by antitrust authorities. However, if the antitrust authorities evaluated the whole process, they would find that it is actually detrimental to consumers. Because this two-step strategy perfectly evades scrutiny, it can eventually achieve the goal of a full merger without any legal challenges, which further explains why firms may want to engage in cross-shareholdings. Viewing cross-ownership as a more attractive corporate strategy, firms disproportionately adopt it without any legal accountability, ultimately to the detriment of consumers. Competition authorities should thus 
reform their current lenient approach by subjecting minority shareholdings to a stricter scrutiny.

\subsection{Profitability in the Dynamic Case}

We can now compute the value function of each firm $i \in I$ that engages in rival cross-shareholdings, which constitute a building block to analyze the profitability of cross-ownership in the dynamic case. The equilibrium discounted sum of operating profits with k-symmetric cross-ownership for a typical firm is given by:

$$
\begin{aligned}
& V_{S}=\int_{0}^{T_{o}} e^{-r t}\left[\left(a-b \sum_{j=1}^{n} q_{j}-c\right) q_{i}\right] d t+\int_{T_{o}}^{T_{i}} e^{-r t}\left[\left(a-b \sum_{j=1}^{n} q_{j}-c\right) q_{i}\right] d t \\
& =\int_{0}^{T_{o}} e^{-r t}\left[\left(a-b k q_{i}-b(n-k) q_{o}-c\right) q_{i}\right] d t+\int_{T_{o}}^{T_{i}} e^{-r t}\left[\left(a-b k q_{i}-c\right) q_{i}\right] d t
\end{aligned}
$$

where the equilibrium extraction paths for each phase are given by (3) and (4) and the exhaustion dates are solutions to (5). It will be useful to explicitly write down the equilibrium discounted sum of operating profits as a function of $(k, n, v, S)$, but the expression is too cumbersome to report here. Instead we choose to numerically examine the dynamic profitability of the k-symmetric cross-ownership under two groups of participation ratios: $y=\frac{k}{n} \leq \frac{1}{2}\left(\frac{n+1}{n}\right)$ and $y=\frac{k}{n}>\frac{1}{2}\left(\frac{n+1}{n}\right)$. The equilibrium discounted sum of profits without cross ownership for an individual firm is given by:

$$
V_{C}=\int_{0}^{T_{C}} e^{-r t}\left[\left(a-b n q_{C}-c\right) q_{C}\right] d t
$$

where

$$
q_{C}(t)=\frac{a-c}{b(n+1)}\left[1-e^{r\left(t-T_{C}\right)}\right], \quad \frac{a-c}{b(n+1)}\left(T_{C}-\frac{1}{r}+\frac{e^{-r T_{C}}}{r}\right)=S
$$

Then a k-symmetric cross ownership is profitable when

$$
G(k, n, v, S)=V_{S}-V_{C}>0
$$

We use the following parameter values: $a=1, b=1, c=0$ and $r=0.1$, and illustrate in Figures 1-4 the gains resulting from a k-symmetric cross-ownership as a function of initial stock $S$ for different levels of cross-ownership when the participation ratio $y=\frac{k}{n} \leq \frac{1}{2}\left(\frac{n+1}{n}\right)$. While 


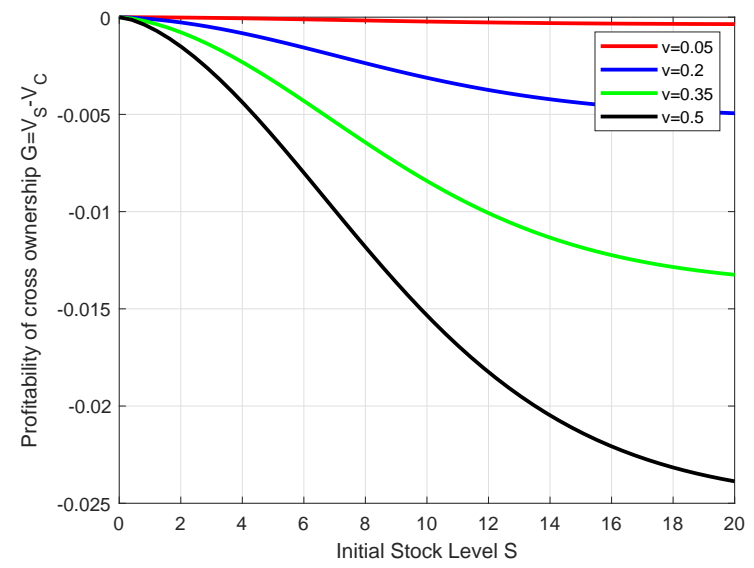

Figure 1: $k=2$ and $n=3$

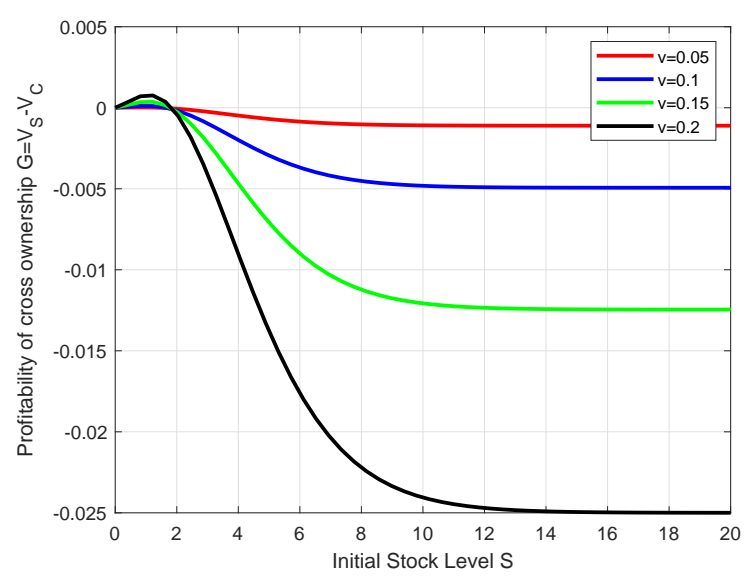

Figure 3: $k=5$ and $n=9$

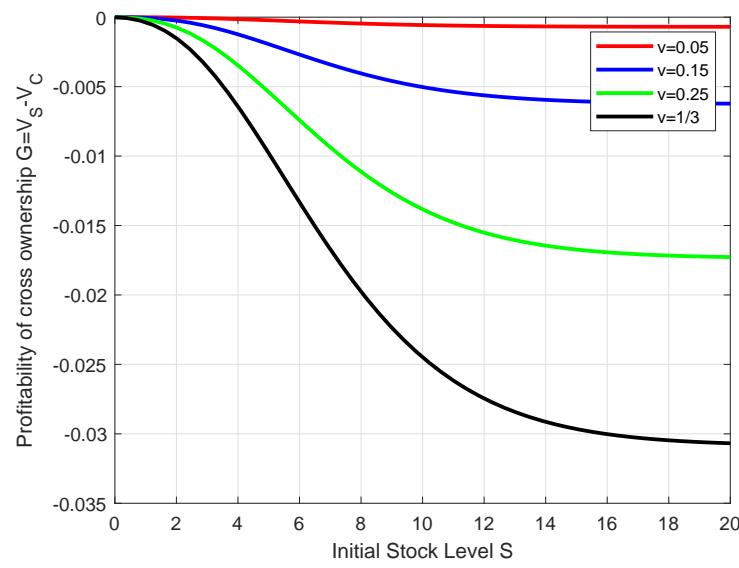

Figure 2: $k=3$ and $n=5$

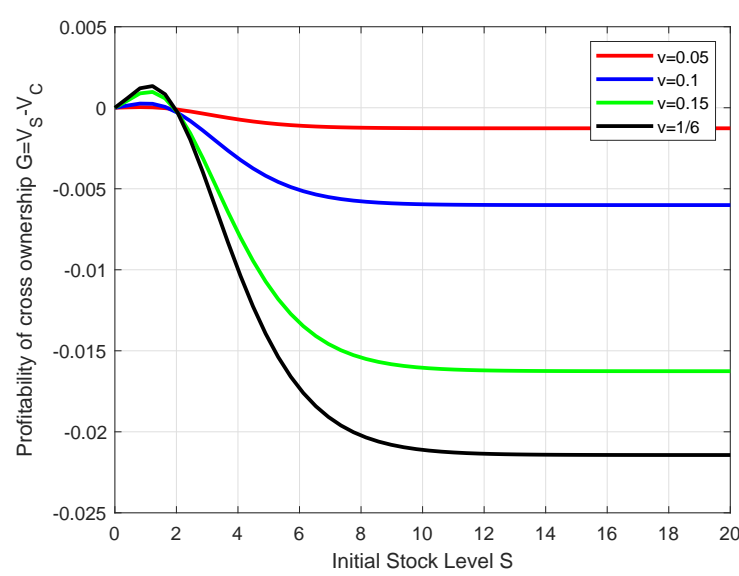

Figure 4: $k=6$ and $n=11$

Figures 1 and 2 show that it is never profitable for firms to engage in cross-ownership for any levels of stock, Figures 3 and 4 indicate that the profitability of cross-ownership can be positive for any $v \in(0,1 / k]$ when the initial stock owned by each firm is small enough. Simulations using many other combinations of $k$ and $n$ (i.e., for all $k=\frac{1}{2} n$ and $k \geq 6$; for all $k=\frac{1}{2}(n+1)$ and $n \geq 7)$ satisfying $y=\frac{k}{n} \leq \frac{1}{2}\left(\frac{n+1}{n}\right)$ also show such findings. These similar findings mean that the previous static results do not necessarily carry over to our dynamic model.

We now move to check if this result holds when the participation ratio $y=\frac{k}{n}>\frac{1}{2}\left(\frac{n+1}{n}\right)$. Using the same parameter values, Figures 5a, 6a and 7a illustrate the gains resulting from a k-symmetric cross-ownership of the $k$ firms as a function of initial stock $S$ in the dynamic case. As a comparison, Figures 5b, $6 \mathrm{~b}$ and $7 \mathrm{~b}$ illustrate the gains resulting from a k-symmetric cross-ownership as a function of cross-ownership $v$ in the static case. With $n=8$ and $k=6$, cross-ownership is always profitable for any $v \in(0,1 / k]$ in the static model. The same holds in the dynamic model for all resource stock levels. With $n=9$ and $k=6$, where the k-symmetric 


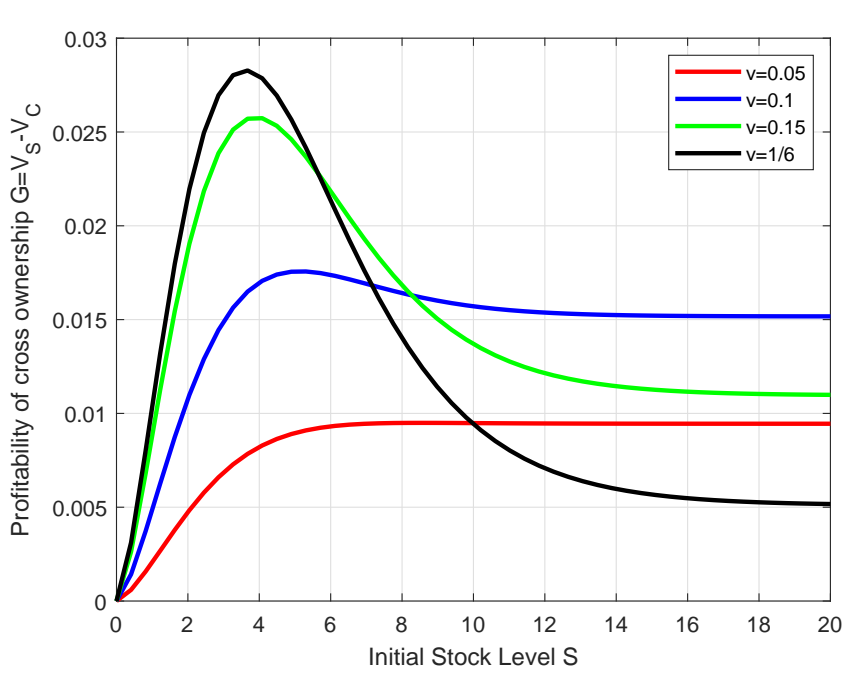

(a) Dynamic Case

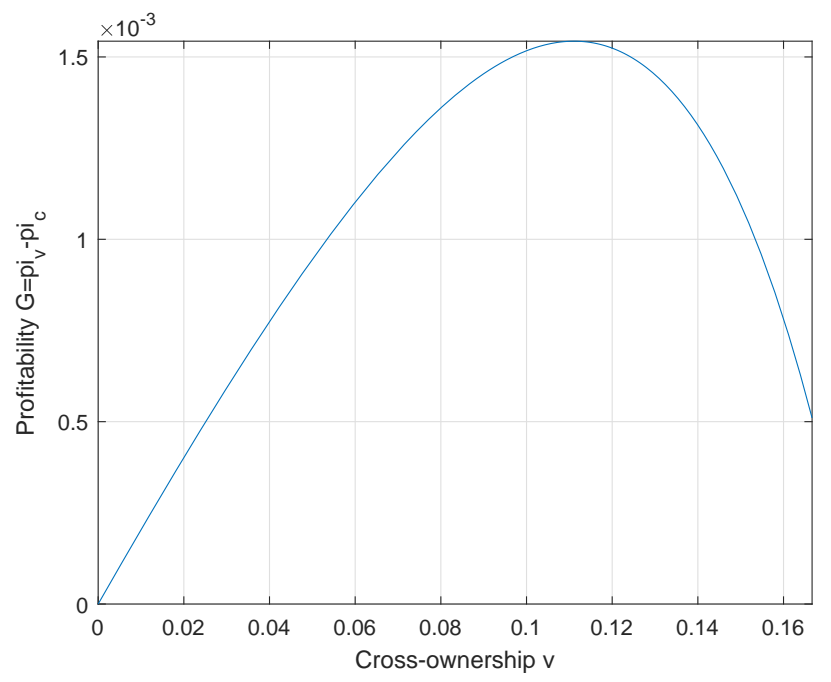

(b) Static Case

Figure 5: $k=6$ and $n=8$

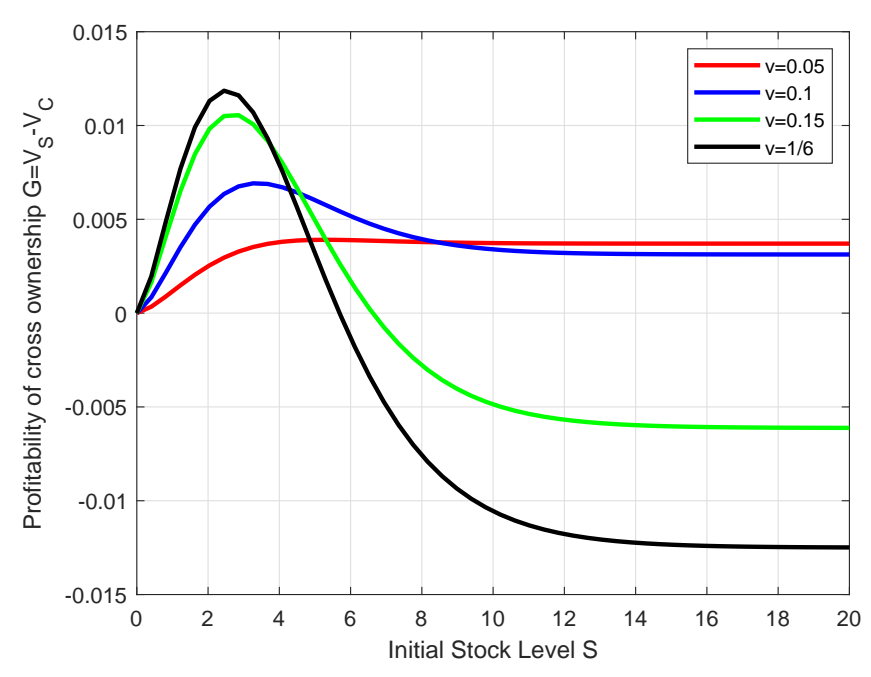

(a) Dynamic Case

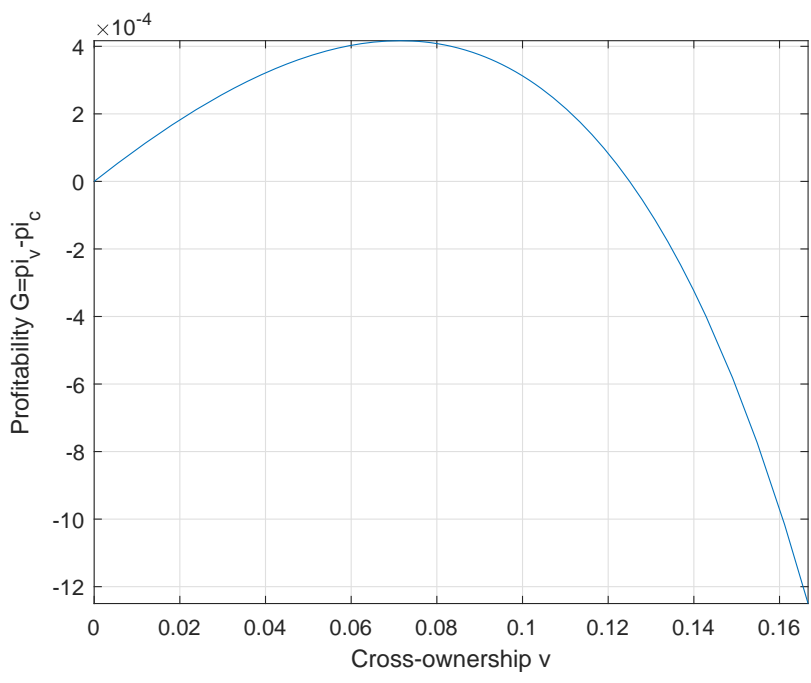

(b) Static Case

Figure 6: $k=6$ and $n=9$

cross-ownership in the static model is not profitable if each of the 6 firms holds more than $12.5 \%$ of the shares of any other firm, it can be profitable in the dynamic model for any levels of cross-shareholdings $v \in(0,1 / k]$ as long as the stock of the firms is small. Moreover, compared to the static case where the k-symmetric cross-ownership for which $k=6$ and $n=10$ is not profitable when $v>6.5 \%$, it can be profitable for any levels of cross-shareholdings $v \in(0,1 / k]$ as long as the stock of the firms is small. In addition, if the initial stock is small, the profitability of k-symmetric cross-ownership increases in $v \in(0,1 / k]$, but this increase in $v$ does not hold if the initial stock is large. Simulations using all other combinations of $k$ and $n$ satisfying $y=\frac{k}{n}>\frac{1}{2}\left(\frac{n+1}{n}\right)$ suggest that these findings are quite robust. 


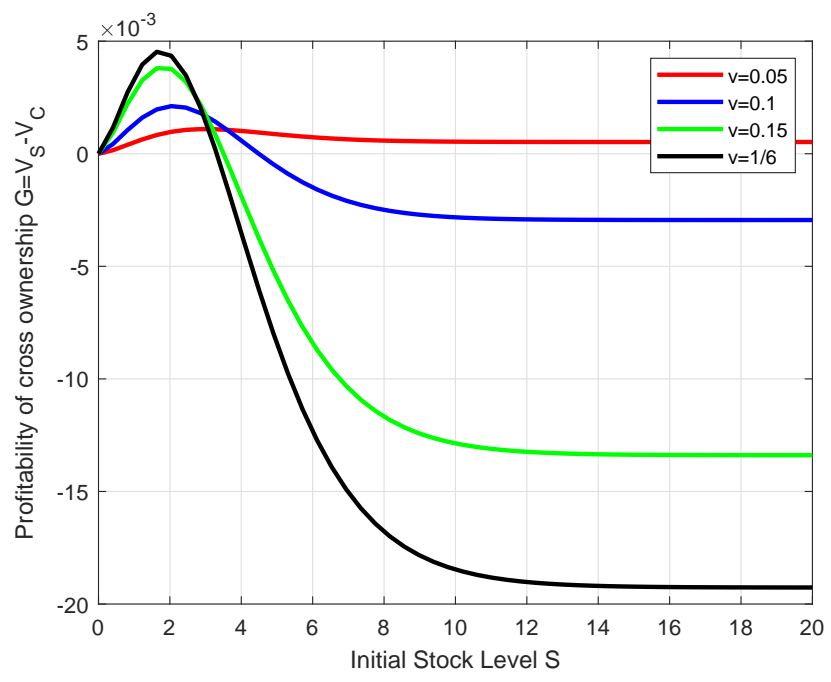

(a) Dynamic Case

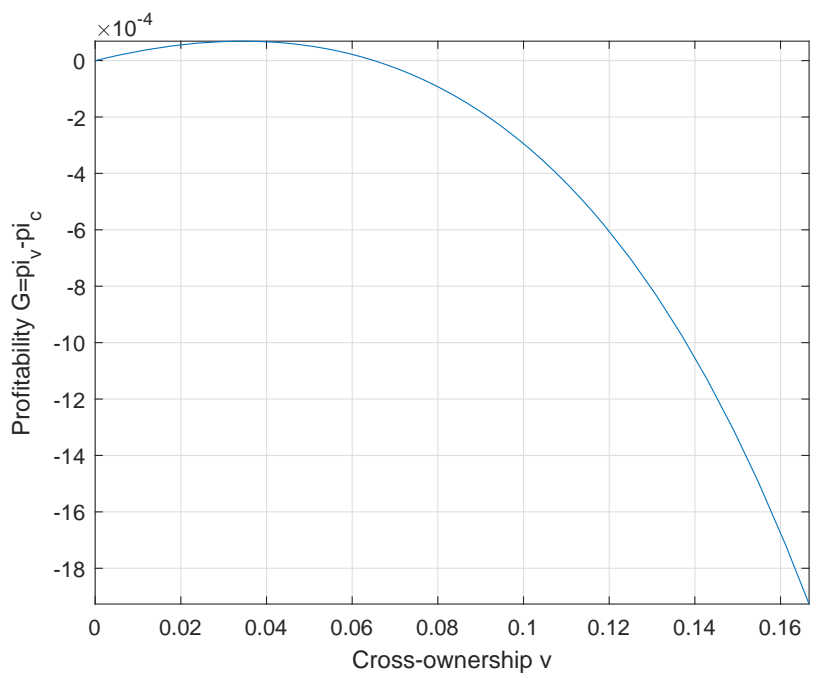

(b) Static Case

Figure $7: k=6$ and $n=10$

Clearly, some of the results from the cross-ownership paradox do not carry over to the case of nonrenewable resource industries. We therefore summarize these findings in Result 2, which is robust to different combinations of $k$ and $n$ and changes in parameter values.

Result 2. The profitability of a k-symmetric cross-ownership can be positive even when the participation ratio $y=\frac{k}{n} \leq \frac{1}{2}\left(\frac{n+1}{n}\right)$ and is always positive when the participation ratio $y=\frac{k}{n}>$ $\frac{1}{2}\left(\frac{n+1}{n}\right)$, provided that the initial resource stock owned by each firm is small enough. Moreover, the profitability of $k$-symmetric cross-ownership increases in $v \in(0,1 / k]$ for $S$ positive and sufficiently small.

Result 2 sharply contrast with the case of a standard Cournot model with cross-ownership but without resource stock constraints. In our earlier static settings, with linear demand and constant marginal cost, a k-symmetric cross-ownership can be profitable even if only $60 \%$ of the firms in the industry participate provided that the cross-shareholdings are small enough. However, in the presence of stock constraints, there exists a range of stock levels for which any levels of cross-ownership can be profitable - the higher the shareholdings, the higher the profitability. Unlike in the static Cournot model with cross-ownership, where outsiders respond to any increased shareholdings between cross-owners by aggressively increasing output and mitigating the cross-ownership participants' gain in market power, here the outsiders are restricted in their response due to their resource constraints. As a result, when the stock levels are sufficiently small, a larger level of cross-ownership will ensure a higher profitability. 
Within our context, the $n-k$ outsiders exhaust their stocks earlier than the cross-ownership participants, resulting in greater induced market power by cross-ownership than in the static model. A similar result can be found in Benchekroun, Breton and Chaudhuri (2019), who find that even a small merger (merger of 2 firms) is always profitable when the resource stock owned by each firm is small enough. The fact that the profitability of a k-symmetric cross-ownership is mostly positive when resource stock owned by each firm is small thus provides an explanation as to why there is so much cross-ownership in the exhaustible sector.

\subsection{Cross-ownership and Resource Extraction}

In this section, we examine the extraction paths and exhaustion dates of firms participating or not in a k-symmetric cross-ownership. Using the same parameter values, Figure 8 plots the stock exhaustion dates $\left(T_{C}, T_{i}, T_{o}\right)$, of a typical firm in the standard Cournot case without cross-ownership, a typical firm $i \in I$ that engages in cross-ownership, and an outsider firm $o \in O$ that remains independent, respectively, for $k=6, n=8$ and $v=0.1$.

As Figure 8 illustrates, $T_{o}<T_{C}<T_{i}$ for any $S$. When $k$ firms engage in a symmetric cross-ownership while the rest of the $(n-k)$ firms remain independent, each of the outsider firms $(o \in O)$ tends to extract from its resource stock faster than in the case without cross-ownership, whereas each of the insider firms $(i \in I)$ extracts the resource more slowly than in the case without cross-ownership. This is in line with cross-ownership theory where, when a firm acquires a partial financial interest in a rival, it has an incentive to compete less aggressively and thus unilaterally reduce its output. This is also consistent with standard oligopoly theory where, for strategic substitutes, a reduction in cross-owners' outputs will result in an expansion of the outsider firms. Simulations using any combinations of $k, n$ with $v \leq 1 / k$ and various values for the parameters $a, b, c$ and $r$ show that this result is qualitatively robust: a $\mathrm{k}$-symmetric cross-ownership induces the outsiders to exhaust their stocks earlier than the cross-ownership participants for any resource stock level.

The main distinguishing feature of a nonrenewable industry is that the overall cumulated extraction is a constant, which is equal to the total resource stock. Using the same parameter values as before, Figure 9 plots the total industry extraction at date 0 under the k-symmetric cross-ownership and the standard Cournot scenario without cross-ownership, as a function of 

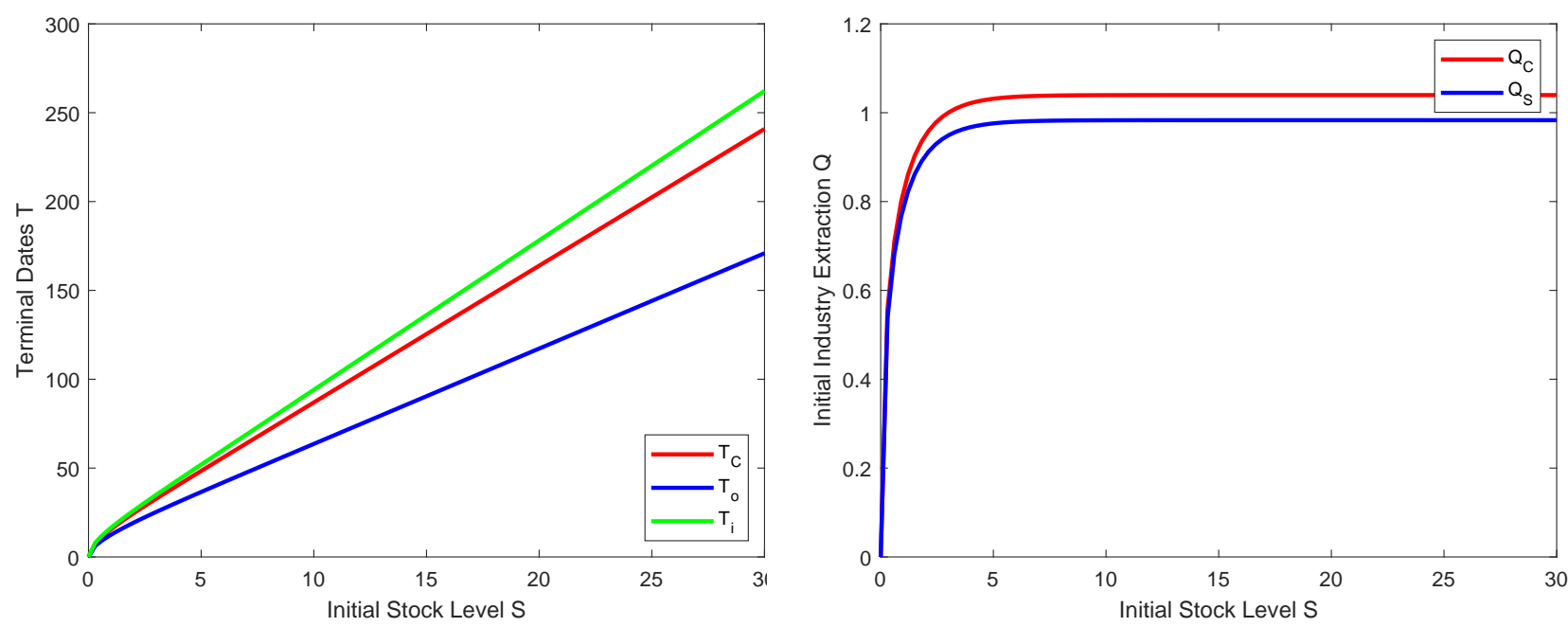

Figure 8: Terminal dates as a function of initial stock

Figure 9: Initial industry extraction as a function of initial stock

the initial resource stock. As Figure 9 illustrates, a k-symmetric cross-ownership results in an initial overall extraction rate that is lower than when there is no cross-ownership for any $S$. Simulations using any combinations of $k, n$ with $v \leq 1 / k$ and various values for the parameters $a, b, c$ and $r$ show that this result is qualitatively robust: a k-symmetric cross-ownership results in a slower extraction rate for the industry at any resource stock level.

These results indicate that after the outsiders exhaust their resource stocks, the resource is eventually supplied by a group of cross-owners, so the degree of concentration in supply will increase over time. These findings bring to mind the 'oil'igopoly theory (Loury, 1986; Polasky, 1992), which predicts that small firms will exhaust their stocks before large firms do, leading to eventual monopolization of the market. The increased concentration over time induced by cross-ownership confers market power on those cross-owners. As a consequence, the cross-ownership participants may raise prices higher than in other industries without stock constraint, thus providing an additional incentive to view the exhaustible sector differently.

\section{Welfare Analysis}

While we have concentrated on the profitability of cross-ownership so far, antitrust authorities should only be concerned with it if it is detrimental to welfare. Therefore, we have to conduct a welfare analysis. In this section, we examine the welfare implications of the $\mathrm{k}$-symmetric cross-ownership under the consumer-surplus (CS) criterion, and compare the results in the 
dynamic model (for a nonrenewable resource industry) with that in the static model (for a more generic industry). ${ }^{13}$ Subsequently, we provide some policy implications from our analysis.

The competition authority is concerned with the consumer surplus change induced by the k-symmetric cross-ownership:

$$
\Delta C S=C S_{v}-C S_{c}=\frac{b}{2} Q_{v}^{2}-\frac{b}{2} Q_{c}^{2}
$$

where $Q_{v}$ and $Q_{c}$ are the equilibrium industry output with and without cross-ownership, respectively. Then,

$$
\Delta C S(k, n, v)=\frac{b}{2}\left(\frac{a-c}{b}\right)^{2}\left[\left(\frac{\left(-k^{2}+n+k\right) v+n}{\left(k+n+1-k^{2}\right) v+n+1}\right)^{2}-\frac{n^{2}}{(n+1)^{2}}\right]
$$

Proposition 3. For any $2 \leq k \leq n$ and $0<v \leq \frac{1}{k}$, a k-symmetric cross-ownership is never welfare-improving when evaluated in accordance with a consumer surplus criterion.

Proof. The CS change can be rewritten as

$$
\Delta C S(k, n, v)=\frac{[v(k(k-1)(2 n+1)-2 n(n+1))-2 n(n+1)] k v(k-1)}{\left(\left(k+n+1-k^{2}\right) v+n+1\right)^{2}(n+1)^{2}}\left[\frac{(a-c)^{2}}{2 b}\right]
$$

For $2 \leq k \leq n$ and $0<v \leq \frac{1}{k}$

$$
\begin{aligned}
v(k(k-1)(2 n+1)-2 n(n+1))-2 n(n+1) & \leq \frac{1}{k}(k(k-1)(2 n+1)-2 n(n+1))-2 n(n+1) \\
& =(k-1)(2 n+1)-\frac{2 n(n+1)}{k}-2 n(n+1) \\
& =k(2 n+1)-(2 n+1)-\frac{2(n+1)}{k}-2 n^{2}-2 n \\
& =2 n(k-n)+k-2 n-(2 n+1)-\frac{2(n+1)}{k}<0
\end{aligned}
$$

Thus,

$$
\Delta C S(k, n, v)<0, \forall v \in\left(0, \frac{1}{k}\right]
$$

\footnotetext{
${ }^{13}$ We also conduct the welfare analysis based on the total surplus criterion, i.e., the sum of the consumer surplus (CS) and total profits of all the firms, where total profits are defined as the combined sum of the operating profits of the cross-ownership participants (belonging to the subset $I$ of 'insiders'), $k \pi_{i}^{v}$, and of the firms outside the cross-ownership (belonging to the subset $O$ of 'outsiders'), $(n-k) \pi_{o}^{v}$. But we do not report it here as the results and policy implications are qualitatively similar to those using CS criterion.
} 
This result is highly intuitive. When firms engage in rival cross-shareholdings, they will compete less aggressively with each other and thus unilaterally reduce their outputs, since any gains from the acquirers' own activities may be offset by a negative impact on the acquirers' share of the targets' profits. Although the outsiders expand their outputs as a response, the reduction in the outputs brought by cross-ownership more than offsets the increase. As a result, the industry output decreases and market price increases, thus decreasing consumer surplus.

We now turn to the welfare analysis in a nonrenewable industry. The consumer surplus generated by the exploitation of the nonrenewable resource under the k-symmetric cross-ownership structure is

$$
\begin{aligned}
C S_{S} & =\int_{0}^{T_{i}} e^{-r t}\left[\frac{b}{2}\left(\sum_{j=1}^{n} q_{j}\right)^{2}\right] d t \\
& =\int_{0}^{T_{o}} e^{-r t}\left[\frac{b}{2}\left(k q_{i}+(n-k) q_{o}\right)^{2}\right] d t+\int_{T_{o}}^{T_{i}} e^{-r t}\left[\frac{b}{2}\left(k q_{i}\right)^{2}\right] d t
\end{aligned}
$$

where the equilibrium extraction paths for each phase are given by (3) and (4) and the exhaustion dates are solutions to (5). The consumer surplus generated by the exploitation of the nonrenewable resource under the standard Cournot model without cross-ownership is given by

$$
C S_{C}=\int_{0}^{T_{C}} e^{-r t}\left[\frac{b}{2}\left(n q_{C}\right)^{2}\right] d t
$$

where

$$
q_{C}(t)=\frac{a-c}{b(n+1)}\left[1-e^{r\left(t-T_{C}\right)}\right], \quad \frac{a-c}{b(n+1)}\left(T_{C}-\frac{1}{r}+\frac{e^{-r T_{C}}}{r}\right)=S .
$$

The competition authority concerns the CS change induced by the k-symmetric cross-ownership in a nonrenewable resource industry:

$$
W(k, n, v, S)=C S_{S}-C S_{C}
$$

It will be useful to explicitly express $W$ as a function of $(k, n, v, S)$, but the expression is too cumbersome to report here. Instead, we choose to numerically examine the dynamic 
percentage CS change of the k-symmetric cross-ownership, and directly compare it with the static percentage CS change, defined as

$$
d(v)=\frac{C S_{v}-C S_{c}}{C S_{c}}
$$

The reason is that when $S$ is large enough, i.e., the resource is abundant, the dynamic CS change will asymptotically converge to the static result. Using the same parameter values as before, we illustrate in Figure 10 the percentage CS change resulting from a k-symmetric cross-ownership as a function of initial stock $S$ for different levels of cross-ownership under participation ratios $y=\frac{k}{n}=\frac{6}{8}$ and $y=\frac{k}{n}=\frac{6}{10}$. The dashed and solid line denote the static and dynamic percentage CS loss, respectively. Figure 10 indicates that a k-symmetric cross-ownership is

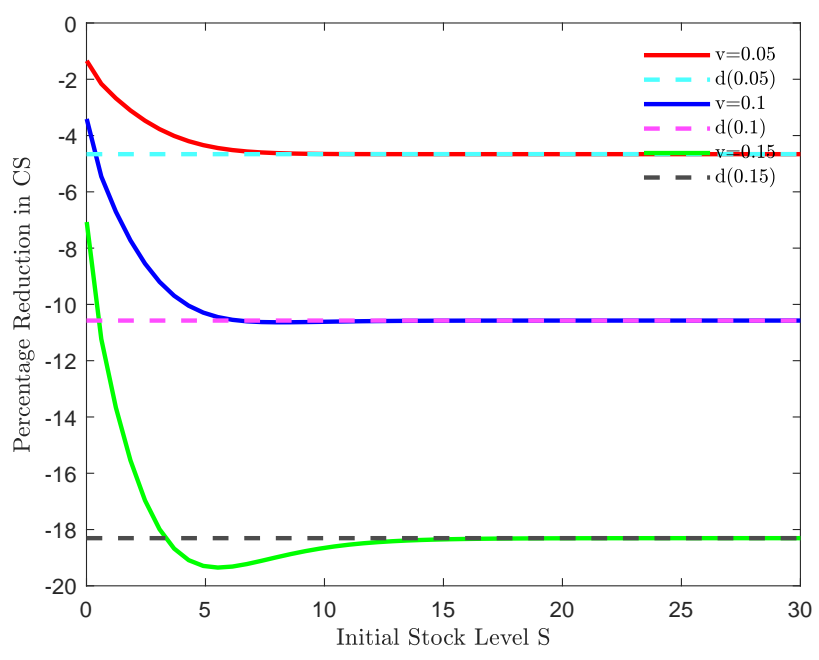

(a) $k=6$ and $n=8$

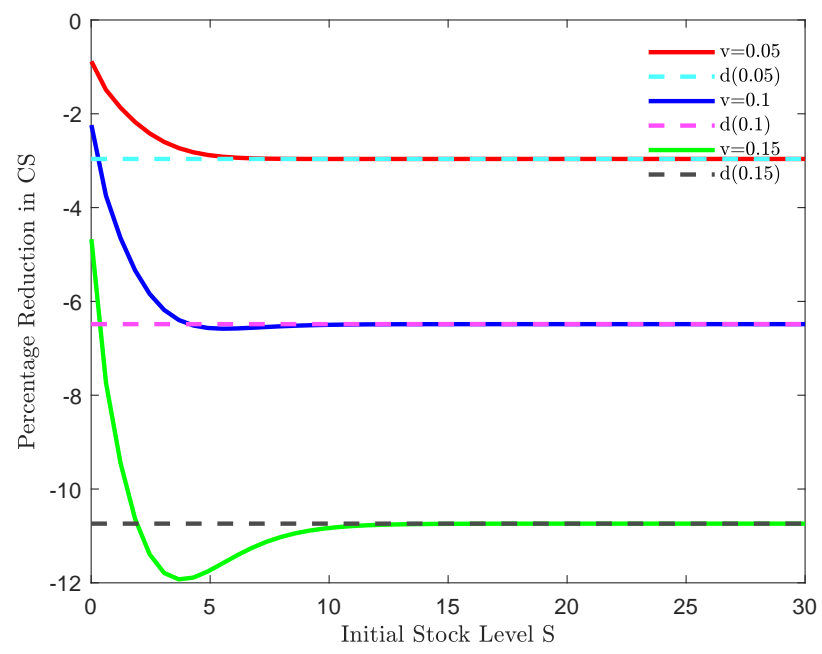

(b) $k=6$ and $n=10$

Figure 10: Percentage CS change as a function of initial stock

never welfare-improving for all $S$ based on a consumer surplus criterion. Simulations using any combinations of $k, n$ with $v \leq 1 / k$ and various values for the parameters $a, b, c$ and $r$ show that this result is qualitatively robust. We also observe the following:

Result 3. When the initial resource stock owned by each firm is small enough, the percentage consumer surplus loss in the dynamic case resulting from a k-symmetric cross-ownership is smaller than that in the static case.

This result seems surprising, as one would expect the exact opposite: the consumer surplus loss is higher in the dynamic case. This is because when resource stock owned by each firm is small enough, a k-symmetric cross-ownership induces the outsiders to exhaust their resource 
stocks before the cross-ownership participants. Consequently, a group of cross-owners will eventually monopolize the market, and thus the price can be raised much higher than in a static model. While result 3 may seem counterintuitive, the main intuition behind it is that although the cross-owners can raise the price much higher, it also extends the duration of the resource that can be used. As the resource becomes increasingly scarce, its extended periods of use partially offset the negative effect of the higher price on the consumer surplus. Therefore, the CS loss is smaller in the dynamic case than the static case when $S$ is small enough. In addition to the scarcity effect, the risk of future trade disruption may also favor a more conservationist extraction path at the cost of higher price, as emphasized in Hillman and Van Long (1983).

In the absence of any potential efficiency gains, our results thus suggest that passive minority cross-shareholdings should be blocked by competition authorities according to a CS standard. However, cross-ownership is generally believed to bring efficiency gains. For example, partial cross-ownership offers a means for providing and compensating capital to risky ventures, for solidifying buyer-seller relationships, for funding and exploiting joint R\&D activities, and for appropriating the returns to technology transfer (Reynolds and Snapp, 1986). From a financial perspective, cross-ownership can help to reduce holdup costs, mitigate financing constraints, and facilitate greater innovation and relation-specific investment, helping to improve in operating efficiency (Nain and Wang, 2018). ${ }^{14}$ Thus, when competition authorities make the tradeoffs between the possible efficiency gains and the CS loss brought by cross-ownership, they should be cautious when ruling in the nonrenewable resource sector. As when the resource stock owned by each firm is small enough, cross-ownership may turn out to be less detrimental to consumers.

\section{Conclusion}

In this paper, we investigate the profitability of a k-symmetric cross-ownership in an oligopolistic industry with linear demand and constant marginal costs of production where firms compete in quantity. We show that a k-symmetric cross-ownership is never profitable for any levels of non-controlling minority shareholdings if the participation ratio $\frac{k}{n}$ is less than or equal to $\frac{1}{2}\left(\frac{n+1}{n}\right)$, while it can be profitable for a large range of cross-ownership beyond that participation

\footnotetext{
${ }^{14}$ It should be noted that these possible efficiency gains are also one of the reasons why firms want to participate in cross-ownership.
} 
ratio. We define this result as a cross-ownership paradox, analogous to the merger paradox. With the presence of stock constraints, however, we find that some of the results from the cross-ownership paradox do not carry over to the case of nonrenewable resource industries. The profitability of a k-symmetric cross-ownership can be positive even when the participation

ratio $\frac{k}{n}$ is less than or equal to $\frac{1}{2}\left(\frac{n+1}{n}\right)$ and is always positive when the participation ratio $\frac{k}{n}$ is greater than $\frac{1}{2}\left(\frac{n+1}{n}\right)$, provided that the initial resource stock owned by each firm is small enough. This outcome occurs because when the cross-owners reduce their output due to their ownership stake in the rival firms, the outsiders are limited in their response in terms of increased output due to their finite resource stocks. Consequently, the cross-ownership participants may raise prices more than in other industries without stock constraint. Our paper also highlights that cross-ownership can be preferable to a full merger in terms of Cournot competition. Not only is it more profitable to participate in the cross-ownership than a horizontal merger, more importantly, it constitutes a shrewd strategy to avoid the possible legal challenges. Thus competition authorities should adapt their current lenient approach towards minority shareholdings to a stricter scrutiny.

\section{References}

Alley, Wilson A. 1997. "Partial ownership arrangements and collusion in the automobile industry." The Journal of Industrial Economics, 45(2): 191-205.

Amundsen, Eirik S, and Lars Bergman. 2002. "Will cross-ownership re-establish market power in the Nordic power market?" The Energy Journal, 23(2).

Benchekroun, Hassan, Alex Halsema, and Cees Withagen. 2009. "On nonrenewable resource oligopolies: The asymmetric case." Journal of Economic Dynamics and Control, 33(11): 1867-1879.

Benchekroun, Hassan, Alex Halsema, and Cees Withagen. 2010. "When additional resource stocks reduce welfare." Journal of Environmental Economics and Management, 59(1): 109-114. 
Benchekroun, Hassan, and Gérard Gaudet. 2003. "On the profitability of production perturbations in a dynamic natural resource oligopoly." Journal of Economic Dynamics and Control, 27(7): 1237-1252.

Benchekroun, Hassan, Gerard van der Meijden, and Cees Withagen. 2019. "An oligopoly-fringe non-renewable resource game in the presence of a renewable substitute." Journal of Economic Dynamics and Control, 105: 1-20.

Benchekroun, Hassan, Michèle Breton, and Amrita Ray Chaudhuri. 2019. "Mergers in nonrenewable resource oligopolies and environmental policies." European Economic Review, 111: $35-52$.

Bresnahan, Timothy F, and Steven C Salop. 1986. "Quantifying the competitive effects of production joint ventures." International Journal of Industrial Organization, 4(2): 155-175.

Brito, Duarte, António Osório, Ricardo Ribeiro, and Helder Vasconcelos. 2018. "Unilateral effects screens for partial horizontal acquisitions: The generalized HHI and GUPPI." International Journal of Industrial Organization, 59: 127-189.

Brito, Duarte, Luís Cabral, and Helder Vasconcelos. 2014. "Divesting ownership in a rival." International Journal of Industrial Organization, 34: 9-24.

Brito, Duarte, Ricardo Ribeiro, and Helder Vasconcelos. 2014. "Measuring unilateral effects in partial horizontal acquisitions." international Journal of industrial organization, 33: $22-36$.

Brito, Duarte, Ricardo Ribeiro, and Helder Vasconcelos. 2018. "Quantifying the coordinated effects of partial horizontal acquisitions." European Economic Review, 110: 108-149.

Dietzenbacher, Erik, Bert Smid, and Bjørn Volkerink. 2000. "Horizontal integration in the Dutch financial sector." International Journal of Industrial Organization, 18(8): 1223-1242.

Farrell, Joseph, and Carl Shapiro. 1990. "Asset ownership and market structure in oligopoly." The RAND Journal of Economics, 275-292. 
Flath, David. 1991. "When is it rational for firms to acquire silent interests in rivals?" International Journal of Industrial Organization, 9(4): 573-583.

Flath, David. 1992. "Horizontal shareholding interlocks." Managerial and Decision Economics, 13(1): $75-77$.

Foros, Øystein, Hans Jarle Kind, and Greg Shaffer. 2011. "Mergers and partial ownership." European Economic Review, 55(7): 916-926.

Fotis, Panagiotis, and Nikolaos Zevgolis. 2016. The competitive effects of minority shareholdings: legal and economic issues. Bloomsbury Publishing.

Gilo, David. 2000. "The anticompetitive effect of passive investment." Michigan Law Review, $99(1): 1-47$.

Gilo, David, Yossi Moshe, and Yossi Spiegel. 2006. "Partial cross ownership and tacit collusion." The Rand journal of economics, 37(1): 81-99.

Hillman, Arye L, and Ngo Van Long. 1983. "Pricing and depletion of an exhaustible resource when there is anticipation of trade disruption." The Quarterly Journal of Economics, 98(2): 215-233.

Hotelling, Harold. 1931. "The economics of exhaustible resources." Journal of political Economy, 39(2): 137-175.

Jovanovic, Dragan, and Christian Wey. 2014. "Passive partial ownership, sneaky takeovers, and merger control." Economics Letters, 125(1): 32-35.

Kumar, B Rajesh. 2012. Mega Mergers and Acquisitions. Springer.

Levin, Dan. 1990. "Horizontal mergers: The 50-percent benchmark." The American Economic Review, 80(5): 1238-1245.

Lewis, Tracy R, and Richard Schmalensee. 1980. "On oligopolistic markets for nonrenewable natural resources." The Quarterly Journal of Economics, 95(3): 475-491.

López, Ángel L, and Xavier Vives. 2019. "Overlapping ownership, R\&D spillovers, and antitrust policy." Journal of Political Economy, 127(5): 2394-2437. 
Loury, Glenn C. 1986. "A theory of'oil'igopoly: Cournot equilibrium in exhaustible resource markets with fixed supplies." International Economic Review, 285-301.

Malueg, David A. 1992. "Collusive behavior and partial ownership of rivals." International Journal of Industrial Organization, 10(1): 27-34.

Nain, Amrita, and Yan Wang. 2018. "The product market impact of minority stake acquisitions." Management Science, 64(2): 825-844.

O'Brien, Daniel P, and Steven C Salop. 2000. "Competitive effects of partial ownership: financial interest and corporate control." Antitrust Law Journal, 67(3): 559-614.

Ono, Hiroshi, Takuya Nakazato, Colin Davis, and Wilson Alley. 2004. "Partial ownership arrangements in the japanese automobile industry; 1990-2000." Journal of Applied Economics, 7(2): 355-367.

Polasky, Stephen. 1992. "Do oil producers act as 'Oil'igopolists?" Journal of Environmental Economics and Management, 23(3): 216-247.

Reynolds, Robert J, and Bruce R Snapp. 1986. "The competitive effects of partial equity interests and joint ventures." International Journal of Industrial Organization, 4(2): 141-153.

Ryan, Stephen P. 2012. "The costs of environmental regulation in a concentrated industry." Econometrica, 80(3): 1019-1061.

Salant, Stephen W. 1976. "Exhaustible resources and industrial structure: A Nash-Cournot approach to the world oil market." Journal of Political Economy, 84(5): 1079-1093.

Salant, Stephen W, Sheldon Switzer, and Robert J Reynolds. 1983. "Losses from horizontal merger: the effects of an exogenous change in industry structure on Cournot-Nash equilibrium." The Quarterly Journal of Economics, 98(2): 185-199.

Stühmeier, Torben. 2016. "Competition and corporate control in partial ownership acquisitions." Journal of Industry, Competition and Trade, 16(3): 297-308.

Takayama, Akira. 1985. Mathematical economics. Cambridge University Press. 
Trivieri, Francesco. 2007. "Does cross-ownership affect competition?: Evidence from the Italian banking industry." Journal of International Financial Markets, Institutions and Money, 17(1): 79-101.

Watkins, William Edwin. 2019. "Essays on Imperfect and Dynamic Competition." Doctoral dissertation. Retrieved from https: // doi. org/10. 17615/taxh-tm16. 